\title{
K. al-maqālāt
}





$$
\text { الرموز }
$$

> > : نقترح حذفه

>> : نقترح إضافته

.... عبارة غير مقروءة

[] [ب: عبارة غير مفهومة 
1. أبمع أهل الإسلام واليهود والنصارى وعامة الجموس وأكثر البراهمة أنّ العالم محدث و ظ حاشية خارجيّة مخلوق. وقالت الدهريّة والثنويّة وعامة الملحدين إنّ العالم قديم.

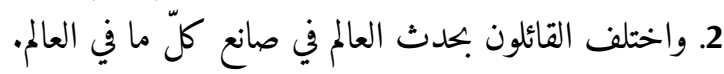

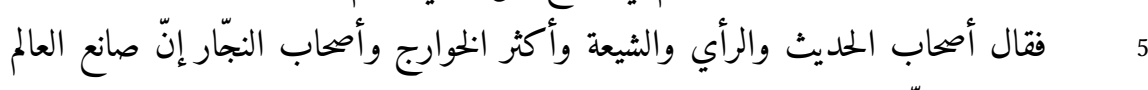
بمجيع ما فيه ربّ العالمين.

وقالت المعتزلة : اكلّ ما في العالم من أفعال العباد مخترعه ومحدثه العباد وليس لله فيه و ظط حاشية عُليا وزعم ثمامة أنّ جميع ما يوجد من متولّدات أفعال العباد في العالم فهو محدث لا خالق . 10

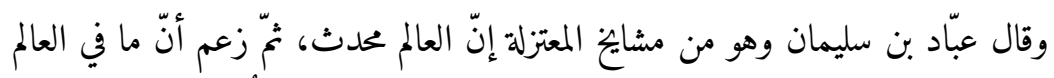

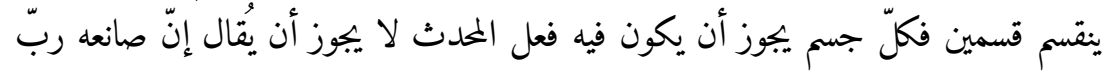

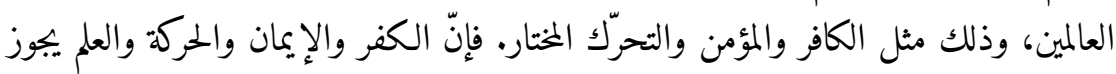

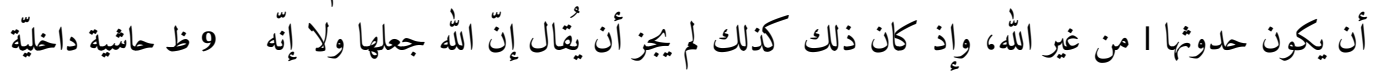

13

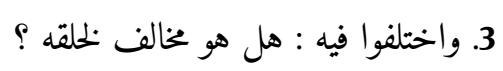

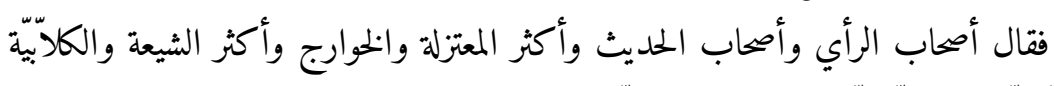

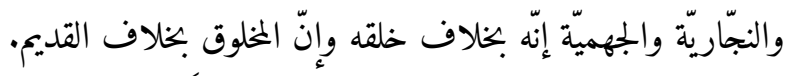

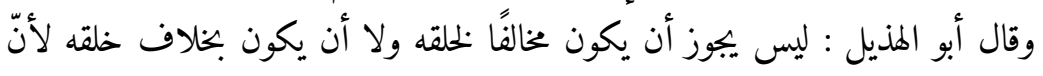

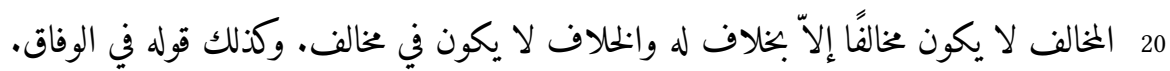

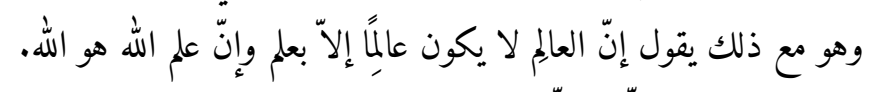

13 ظ حاشية خارجيّة 4. - 2 - واختلفوا في ماهيّة الربّ. 


\section{De Dieu}

\section{Éternité et création du monde}

1. a. Les musulmans, les juifs, les chrétiens, l'ensemble des mazdéens et la majorité des brahmanes s'accordent à penser que le monde est adventice et qu'il est créé.

b. Pour les matérialistes, les dualistes et l'ensemble des hérétiques, le monde est éternel.

\section{Qui est l'Artisan des choses du monde}

2. Ceux pour qui le monde est adventice s'opposent quant à savoir qui est l'Artisan de tout ce qui existe dans le monde.

a. Ainsi, les traditionnistes et les partisans de l'opinion personnelle, les chiites, la majorité des hāariğites et les disciples d'al-Nağğār soutiennent que l'Artisan du monde et de tout ce qui s'y trouve est Dieu.

$b$. Selon les mu'tazilites, ce sont les hommes qui créent et font advenir les actes humains [qui se trouvent] dans le monde. Dieu n'y prend aucune part.

c. Tumāma prétend que l'ensemble des [actes] engendrés par les actes humains dans le monde sont adventices et n'ont pas de créateur.

d. Selon 'Abbād b. Sulaymān, l'un des maîtres mu'tazilites, le monde est adventice. Puis il prétendit que tout ce qui s'y trouve est de deux sortes [et qu'] on ne saurait dire d'un corps susceptible de recevoir un acte [provenant d'un être] adventice qu'il est fabriqué par Dieu. Ainsi en est-il du mécréant, du croyant et des [corps] qui se meuvent de leur libre choix, et cela parce que la mécréance, la croyance, le mouvement et la science peuvent advenir de quelqu'un d'autre que Dieu. Puisqu'il en est ainsi, on ne peut dire ni que Dieu les rend tels ni qu'Il ne les a pas créés.

\section{Est-Il différent de Sa Création ?}

3. Ils s'opposent à Son sujet : est-Il différent de Sa création?

a. Les tenants de l'opinion personnelle et les traditionnistes, la majorité des mu'tazilites, les haāriğites, la majorité des chiites, les kullābites, les nağğārites et les ğahmites disent qu'Il diffère de Sa création et que le créé diffère de l'Éternel.

b. Selon Abū al-Hudayl, Il ne peut être différent de Sa création ni différer d'elle car le différent ne l'est que par une différence lui appartenant et cette différence ne peut être dans un différent. Il en va de même pour la convenance.

c. Il affirme pourtant que le savant n'est savant que par une science et que la Science de Dieu est [identique à] Dieu.

\section{De la quiddité de Dieu}

4. Ils s’opposent au sujet de la quiddité du Seigneur. 
فقال قوم : للربّ ماهيّة لا يعلمها إلاّ هو، وهو قول ضرار وبرغوث وحفص الفرد،

$$
\text { ويقُال أنه قول أبي حنيفة. }
$$

وقال متكلّمو أهل الحديث والمعتزلة والنجّاريّة وغيرهم : القول بالماهيّة في الله عزّ وجلّ وحلّ قول محال.

$$
5
$$

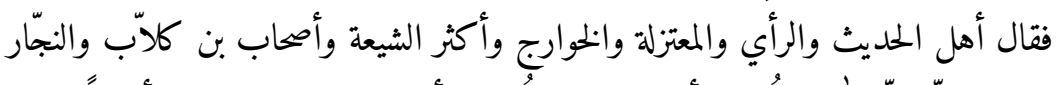

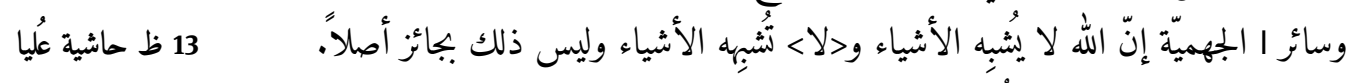

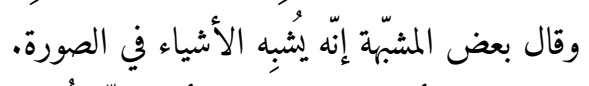

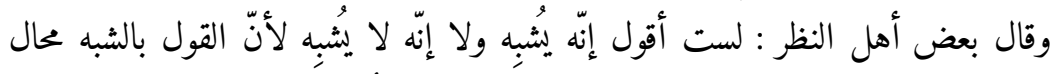

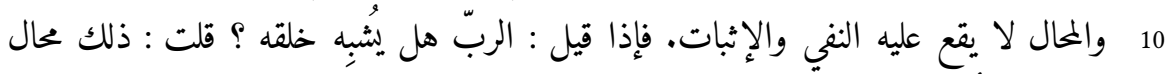

13 ظ حاشية داخليّة والمحال لا يُقال فيه ا يكون أو لا لا يكون.

6. القدم والحياة والبقاء صفات بان بها عن المحدث ليست هي الله ولا غيره، وهو 13 ظط حاشية خارجيّة قول أهل الحتّ.

وقالت المعتزلة بنغي هذه الصفات.

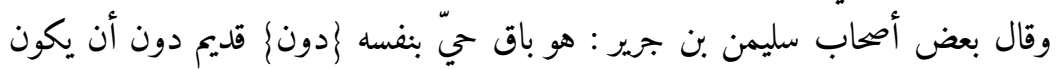
له حياة أو بقاء أو قدم. وكان يقول : له علم وقدرة وسمع وبصر وإرادة.

15 و حاشية خارجيّة

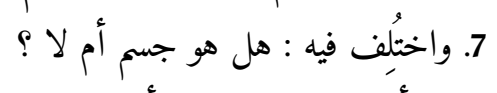

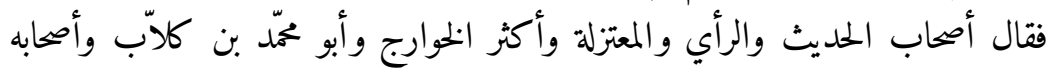

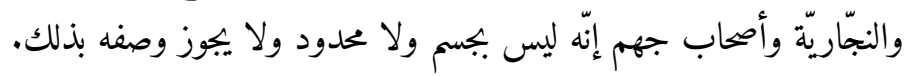

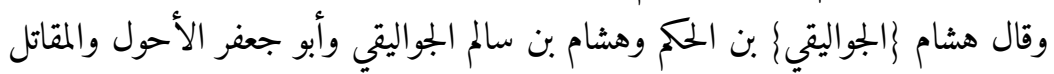

15 و حاشية عُليا ا والسكّك : هو جسم له مقدار، طويل عريض >عميق> عند أُ أكثر هؤلاء.

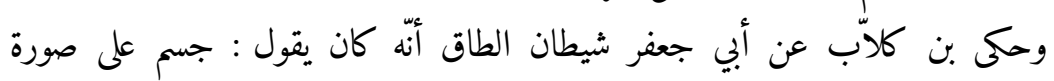
الإنسان وهو سبعة أشبار. وحكى عن هشام بن الحكم من أنه كان يقول : هو سبعة أشبار.

19 جهم] وقد تُقرأ جهنم 20 الجواليقي'] خطّ فوق الكلمة لحذفها 21 عميق] اقتراح م. راشد 24 هو] فوق 
a. Selon certains, le Seigneur possède une quiddité qu'Il est seul à connaître. C’est la thèse de Ḍirār, de Burgūū et de Ḥafṣ al-Fard, et l'on dit que c'est [également] celle d'Abū Hanīfa.

$b$. Selon les théologiens traditionnistes, les mu'tazilites, les naǧğārites et d'autres, parler de la quiddité de Dieu, exalté soit-Il, est [une chose] impossible.

\section{Dieu ressemble-t-Il à Ses actes et à Ses artefacts ?}

5. Ils s'opposent à Son sujet : ressemble-t-Il à Ses actes et Ses artefacts ?

a. Les traditionnistes et les tenants de l'opinion personnelle, les mu'tazilites, les haāriğites, la majorité des chiites, les disciples d'Ibn Kullāb, al-Nağğār et l'ensemble des ğahmites disent que Dieu ne ressemble à nulle chose et nulle chose ne Lui ressemble, et que cela n'est même pas possible.

b. Selon certains assimilationnistes, Il ressemble aux choses par la forme.

c. Certains spéculateurs disent : « Je ne dis pas qu'Il ressemble [à Ses créatures] ni qu'Il ne [leur] ressemble pas, car parler de ressemblance est impossible et l'impossible ne fait l'objet ni de négation ni d'affirmation. Si donc l'on demande: 'Le Seigneur ressemble-t-Il à Sa création ?', je réponds : 'Cela est impossible, et on ne dit de l'impossible ni qu'il est ni qu'il n'est pas'. »

\section{Des attributs de Dieu}

6. a. L'Éternité, la Vie et la Durée sont des attributs qui Le séparent du créé et qui ne sont ni [identiques à] Dieu ni autres que Lui. C'est la thèse de ceux qui sont dans le vrai.

$b$. Les mu'tazilites nient l'existence de tels attributs.

c. Selon certains disciples de Sulaymān b. Ǧarīr, Il est durant, vivant par luimême et éternel, sans posséder de Vie, de Durée ou d’Éternité. [Sulaymān] dit également: Il possède une Science, une Puissance, une Ouïe, une Vue et une Volonté.

\section{Dieu est-Il ou non un corps?}

7. Il y a opposition à Son sujet : est-Il ou non un corps?

a. Selon les traditionnistes et les tenants de l'opinion personnelle, les mu'tazilites et la majorité des hāariǧites, ainsi qu'Abū Muhammad b. Kullāb et ses disciples, les nağğārites et les disciples de Ğahm, Il n'est pas un corps, Il n’a pas de limite et il n'est pas possible de Lui attribuer de telles choses.

b. Selon Hišām b. al-Ḥakam, Hišām b. Sālim al-Ǧawālīqī, Abū Ğa 'far al-Ahwal, Muqātil et al-Sakkāk, Il est un corps doté de dimensions, long, large 〈et profond〉 pour la majorité d'entre eux.

c. Au rapport d'Ibn Kullāb, Abū Ğa'far Šayțān al-Ṭāq dit qu'Il est un corps à forme humaine, et Il mesure sept empans.

d. Il rapporte également que Hišām b. al-Ḥakam dit : Il mesure sept empans. 
وحكى بن كلاّب عن مقاتل بن سليمان أنه على العرش وأنه أكبر الأشياء إلاّ أنه ا ا 15 و حاشية داخليّة وقالت طائفة من اليهود ومنهم رأس الجالوت بمثل مقالة مقاتل، إلاّ أنّ اليهود تقول إنّه أبيض الرأس والملية.

15 ظ خاشية خارجيّة

$$
5
$$

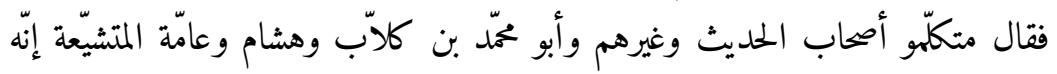

$$
\begin{aligned}
& \text { نور لا كالأنوار، } \\
& \text { غير أنّ أهل الحديث يقولون : ليس يُدرى شعاع ولا ضوء. }
\end{aligned}
$$

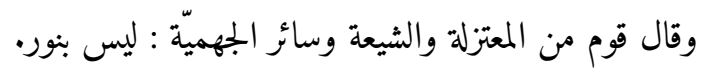

$$
\begin{aligned}
& 10
\end{aligned}
$$

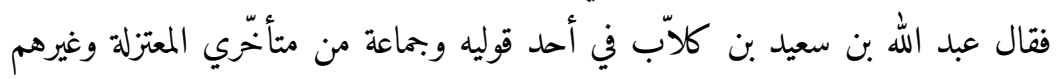

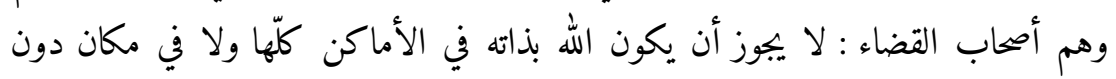

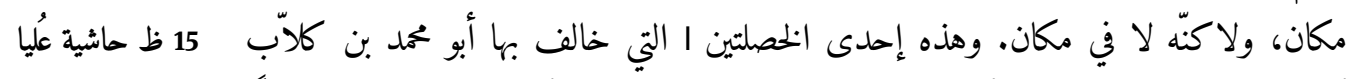

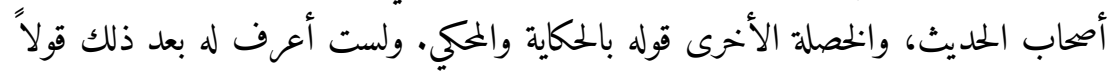
15

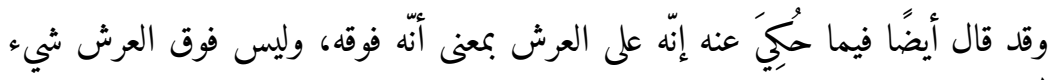
غير الله فهو فوق العرش لا فِي مكان.

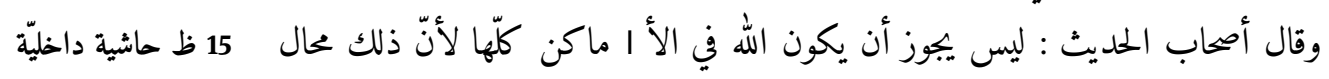

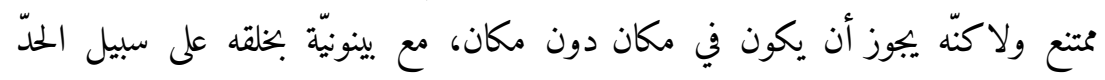
15 ظ حاشية سُفلى 20 وحكى بن كلآب عن بعض البصريّن أنّ الله عزّ وجلّ في كلّ مكان وأنّ الرؤية عليه

وحكى عن الجواربي أنه قال إنّ الله لا يرى ما خلقه حتى يلتفت. قال : ولم أسمع أحدًا جائزة. يقول : سمعت هذا منه. وقال النظّام في كتاب التوحيد إنّه في كلّ شيء ولا يجوز أن لا يكون في كلّ مكان.

5 هل] فوق السطر 9 الجهميّة ] الجهية 17 فوق] + إلا ولعلّها لا مشطوبة 18 الأماكن] الاماكان 
e. Au rapport d'Ibn Kullāb, Il est selon Muqātil sur le Trône et il s'agit de la plus grande des choses ; mais Il est néanmoins un corps.

$f$. Un groupe de juifs, dont l'Exilarque, défendent une thèse similaire à celle de Muqātil, à ceci près que, pour eux, Il a la barbe et les cheveux blancs.

\section{Dieu est-Il ou non lumière?}

8. Ils s'opposent au sujet de [Dieu] : est-Il ou non lumière?

a. Selon les théologiens traditionnistes et d'autres, Abū Muhammad b. Kullāb, Hišām, et l'ensemble des chiites, Il est une lumière différente des autres lumières.

b. Toutefois, selon les traditionnistes, on ne sait pas s'll est rayon ni s'Il est lueur.

c. Selon un groupe de mu'tazilites et de chiites ainsi que l'ensemble des ğahmites, Il n'est pas lumière.

\section{Dieu est-Il en tout lieu?}

9. Ils s'opposent à Son sujet : Lui est-il possible d'être en tout lieu ?

a. Selon l'une des deux thèses de 'Abdallāh b. Sa'īd b. Kullāb à ce sujet, et selon un groupe de mu'tazilites tardifs et d'autres encore - il s'agit des tenants du Décret divin -, il n'est pas possible que Dieu soit dans Son essence en tout lieu ni dans un lieu à l'exclusion d'un autre, mais [Il est] plutôt non dans un lieu. C'est l'un des deux points qui oppose Abū Muhammad b. Kullāb aux traditionnistes, l'autre étant sa thèse sur la citation [de la Parole de Dieu] et la chose citée. À part cela, je ne lui connais aucune thèse que récuseraient les traditionnistes.

b. On rapporte également que, selon lui, [Dieu] est sur le Trône, c'est-à-dire audessus du Trône, et que rien d'autre que Dieu n'est au-dessus du Trône. Il est donc au-dessus du Trône non dans un lieu.

c. Selon les traditionnistes, il n'est pas possible pour Dieu d'être en tout lieu car cela est [une chose] impossible et inconcevable, mais il Lui est possible d'être dans un lieu à l'exclusion d'un autre, avec une séparation de Sa créature faisant office de limite, de point de contiguïté et de contact.

d. Au rapport d'Ibn Kullāb, selon certains Basriens, Dieu, exalté soit-Il, est en tout lieu et Il Lui est possible de voir [Sa création].

e. [Ibn Kullāb] rapporte également d'al-Ǧawāribī que Dieu ne voit pas ce qu'Il a créé avant de se retourner. [Mais] il ajoute : Personne, à ma connaissance, n’affirme l'avoir entendu dire une chose pareille.

f. Dans son K. al-Tawhīd, al-Naẓz̄ām affirme que [Dieu] est en toute chose et qu'il ne Lui est pas possible de ne pas être en tout lieu. 
10 I. De Dieu

وقالت الجهميّة ومَن تابعها من النجّاريّة : يجوز أن يكون القديم عزّ وجلّ في الأماكن 15 ظ حاشية خارجيّة

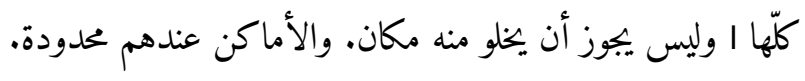


g. Selon les ğahmites et les nağğărites qui partagent leur point de vue, il est possible que l'Éternel, exalté soit-Il, soit en tout lieu, et il n'est pas possible qu'un lieu En soit dépourvu - les lieux étant, selon eux, dotés de limite. 
10. المسطور في الكخاب قول أهل الحديث ومقلّدوها وهشام بن الحلم وأصحابه وعامة 21 و وحاشية خارجيّة

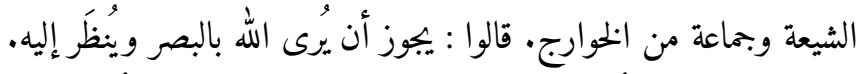

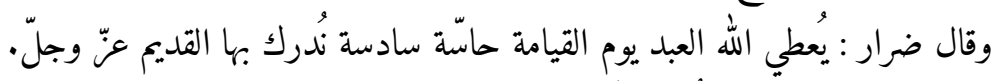

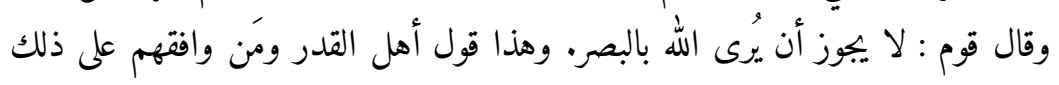

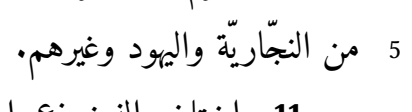

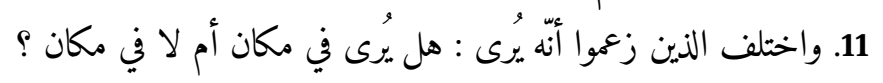

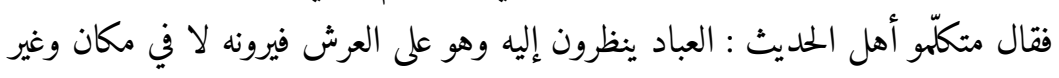
محدود، وقد يجوز أن يرونه لا في مكان.

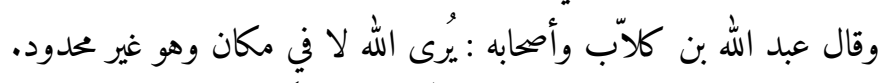

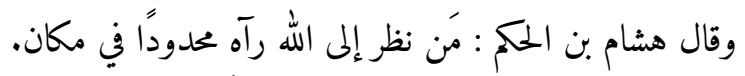

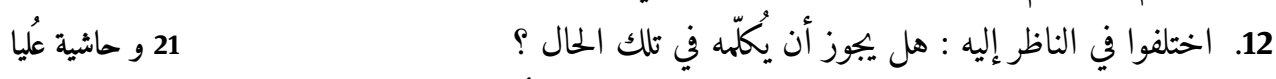

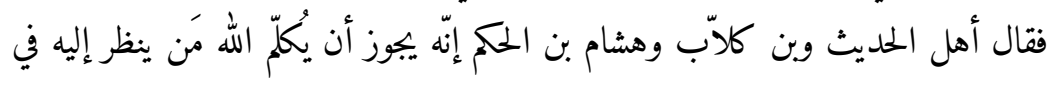

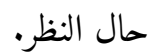
وقال المكّي : لا يُكلمهم في وقت ما ينظرون إليه. 13. واختلفوا في جواز النظر إليه في دار الدنيا.

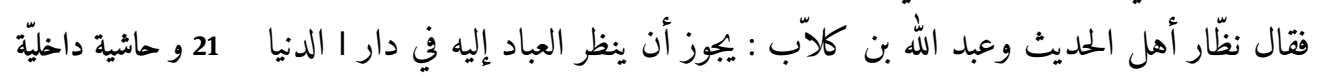
وفي الآخرة إذا قوّى الله أبصارهم.

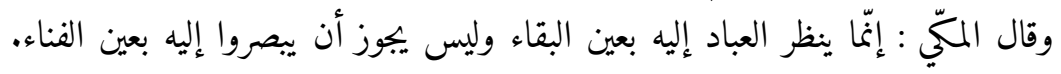
وتابعه على ذلك جماعة من الصوفيّة. (21 21

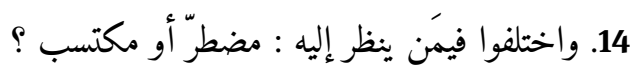




\section{De la vision de Dieu}

\section{Est-Il vu par les regards?}

10. a. Consignée dans le Livre, la thèse des traditionnistes et de ceux qui se conforment à [leurs vues], de Hišām b. al-Ḥakam et ses disciples, de l'ensemble des chiites et d'un groupe de hăriǧites : selon eux, Dieu peut être vu et regardé par les regards.

b. Selon Dirār, Dieu confère à Son serviteur le Jour de la Résurrection un sixième sens par lequel nous appréhendons l'Éternel, exalté soit-Il.

c. Certains soutiennent que Dieu ne peut être vu par les regards. C'est la thèse des qadarites et de ceux qui partagent leur opinion sur ce point, comme les nağğarites, les juifs et d'autres [groupes].

\section{Dieu est-Il vu dans un lieu?}

11. Il y a opposition parmi ceux qui soutiennent qu'on peut voir [Dieu] : est-Il vu dans un lieu ou non dans un lieu?

a. Les théologiens traditionnistes disent que lorsque les hommes Le regardent sur Son Trône, ils Le voient non dans un lieu et [en tant qu'Il est] non délimité, et qu'il est [tout à fait] possible de Le voir non dans un lieu.

b. Selon 'Abdallāh b. Kullāb et ses disciples, Dieu est vu non dans un lieu et [en tant qu'Il est] non délimité.

c. Selon Hišām b. al-Ḥakam, celui qui regarde Dieu Le voit délimité dans un lieu.

\section{Statut de celui qui regarde Dieu}

12. Ils s'opposent au sujet de celui qui regarde [Dieu] : Ce dernier peut-Il lui adresser la parole dans cet état?

a. Selon les traditionnistes, Ibn Kullāb et Hišām b. al-Ḥakam, Dieu peut adresser la parole à ceux qui Le regardent au moment du regard.

b. Selon al-Makkī, Il ne leur parle pas pendant qu'ils Le regardent.

\section{Vision de Dieu ici-bas}

13. Ils s'opposent quant à Sa vision ici-bas.

a. Selon les spéculateurs traditionnistes et 'Abdallah b. Kullāb, il est possible aux hommes de Le voir ici-bas et dans l'au-delà si Dieu raffermit leurs regards.

$b$. Selon al-Makkī, les hommes Le regardent uniquement avec «l'œil permanent ». Il ne leur est pas possible de Le voir avec «l'œil corruptible». Un groupe de mystiques partageaient son opinion à ce sujet.

\section{Statut de l'acte en question}

14. Ils s'opposent au sujet de celui qui regarde [Dieu] : est-il contraint ou acquérant [son acte] ? 
14 II. De la vision de Dieu

فقال أهل الحديث وعبد الله بن كلآب : هو مكتسب لأنه قادر على التغميض، والآخرة ليست دار تكليف. وقال قوم : هم مضطرّون إلى ذلك.

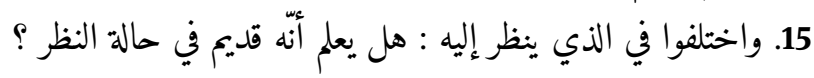
5

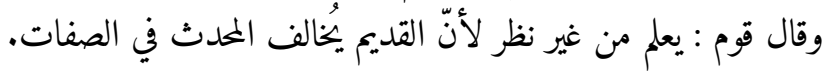


a. Selon les traditionnistes et 'Abdallāh b. Kullāb, il est acquérant parce qu'il peut fermer les yeux et que l'on n'est pas légalement chargé dans l'au-delà.

$b$. Selon certains, [les hommes] sont contraints [de Le regarder].

\section{Sait-on au moment du regard qu'll est Éternel ?}

15. Ils s'opposent au sujet de celui qui regarde [Dieu] : sait-il qu'Il est Éternel au moment où il Le regarde?

a. Selon les traditionnistes et d'autres [groupes], on ne le sait qu'en Le regardant.

b. Selon certains, on le sait sans regarder car l'Éternel diffère de l'adventice par Ses attributs. 
16. وحكى محمّ أبو عيسى الورّاق عن قوم أنّ الصفات ليست موجودة ولا معدومة 27 و حاشية سُفلى ولا مذكورة ولا معلومة ولا بجهولة.

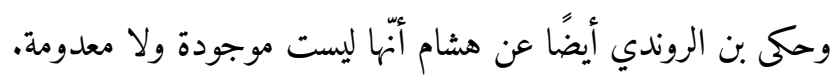

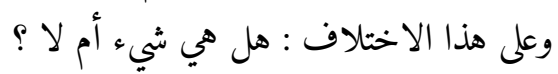

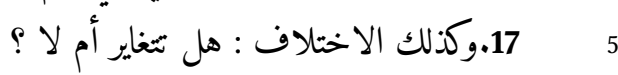
فقال قوم : صفات القديم وصفات المحدث مغايرة. وقال قوم : ليست مغايرة.

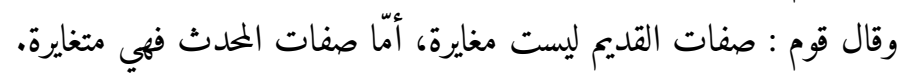

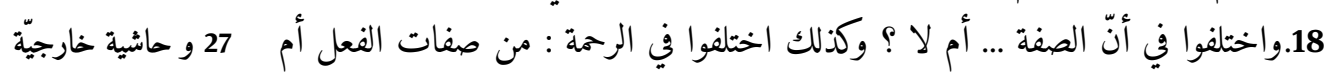

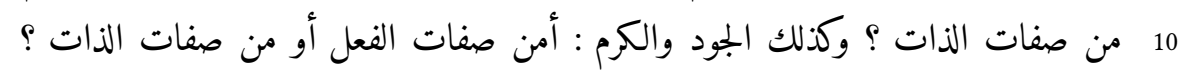
وكذى القول في الحكمة.

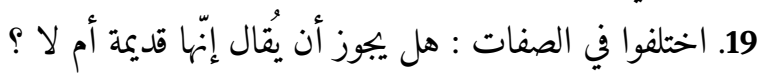

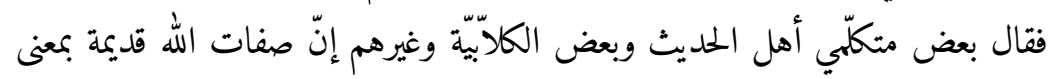

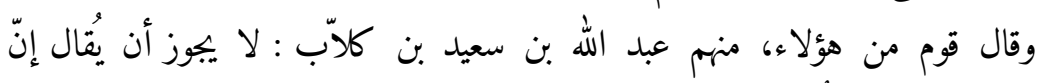
15

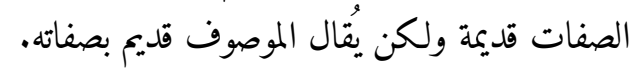

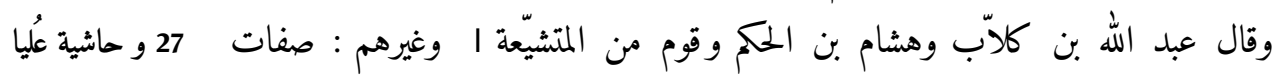
القديم ليست بقديمة ولا محدثة.

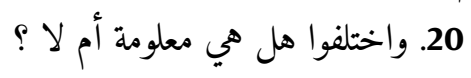

1 أبو] بن 6 صفات] مكرّة 9 الصفة] + كلمة أو كلمتين غير مقروعتين 10 وكنلك] كذالك 15 هؤلاء] 


\section{Des attributs de Dieu}

\section{Les attributs ne sont ni existants ni inexistants}

16. a. Au rapport de Muhammad Abū 'Īsā al-Warrāq, certains disent que les attributs [de Dieu] ne sont ni existants ni inexistants, ni exprimables, ni connaissables ni inconnaissables.

b. De même, Ibn al-Rāwandī rapporte que selon Hišām, ils ne sont ni existants ni inexistants.

c. D’où le désaccord : sont-ils ou non des choses ?

\section{Se distinguent-ils les uns des autres?}

17. De même pour cet autre désaccord : [les attributs] se distinguent-ils ou non les uns des autres?

a. Selon certains, les attributs de l'Éternel ainsi que ceux des [êtres] adventices se distinguent les uns des autres.

b. Selon certains autres, ils ne se distinguent pas les uns des autres.

c. Et selon d'autres, les attributs de l'Éternel ne se distinguent pas les uns des autres (muġāyira) alors que ceux des [êtres] adventices se distinguent les uns des autres (mutå̄āyira).

\section{Répartition de certains attributs en attributs de l'essence et de l'acte}

18. Ils s'opposent quant à savoir si l'attribut est ... ou non. De même pour leur opposition au sujet de la Miséricorde : compte-t-elle parmi les attributs de l'acte ou les attributs de l'essence ? De même pour la Générosité et la Munificence : comptentelles parmi les attributs de l'acte ou les attributs de l'essence? Et il en va de même pour la Sagesse.

\section{Les attributs sont-ils éternels?}

19. Ils s'opposent au sujet des attributs : faut-il dire ou non qu'ils sont éternels ?

a. Selon certains théologiens traditionnistes et certains kullābites et d'autres, les attributs de Dieu sont éternels (qadìma) en tant que pré-éternels (azaliyya) et non en tant qu'ils sont qualifiés par l'éternité.

b. Parmi eux, certains comme 'Abdallāh b. Sa'īd b. Kullāb disent : «Il ne faut pas dire que les attributs sont éternels. On dit que Celui qui est qualifié est éternel avec les attributs [qui le qualifient]».

c. Selon 'Abdallāh b. Kullāb, Hišām b. al-Ḥakam et certains chiites et d'autres, les attributs de l’Éternel ne sont ni éternels ni adventices.

\section{Les attributs sont-ils connaissables ? Existants?}

20. Ils s’opposent quant à savoir si [les attributs] sont ou non connaissables. 
فقال متكلمّو أصحاب الحديث والكلابيّة وغيرهم إنّ صفات الله معلومة لمن علمها مجهولة لمن جهلها.

وقال قوم ليست بمعلومة ولا بجهولة.

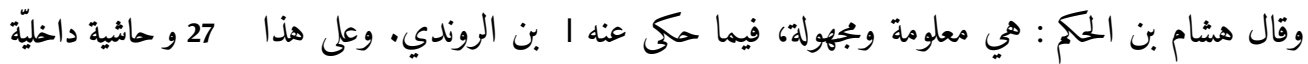

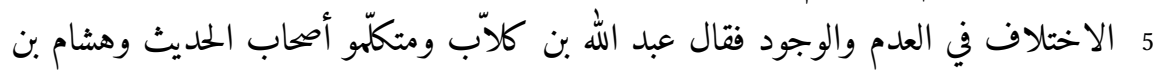
الحكم إنّ صفات الله >غير> موجودة غير معدومة. 
a. Selon les théologiens traditionnistes, les kullābites et d'autres, les attributs de Dieu sont connaissables pour ceux qui les connaissent et inconnaissables pour ceux qui les ignorent.

$b$. Selon certaines personnes, ils ne sont ni connaissables ni inconnaissables.

c. Selon Hišām b. al-Ḥakam, au rapport d'Ibn al-Rāwandī, ils sont connaissables et inconnaissables.

d. Il en va de même pour l'opposition quant à leur inexistence et leur existence. Ainsi, selon 'Abdallāh b. Kullāb, les théologiens traditionnistes et Hišām b. alHakam, les attributs de Dieu ne sont $\langle$ ni $\rangle$ existants ni inexistants. 
21. قال متكلّمو أهل الحديث وأصحاب بن كلاّب والنجّاريّة وأكثر المعتزلة والشيعة : 29 و حاشية خارجيّة كلّ فاعل فله فعل وليس ييجوز أن يكون فاعلاً لا فعل له. له.

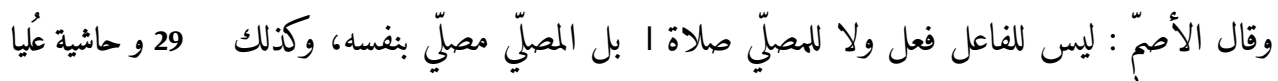

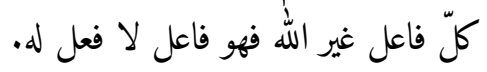
5 22. واختلفوا في ماهيّة الفعل وتغايره.

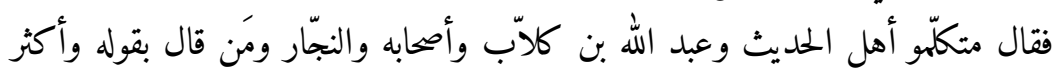

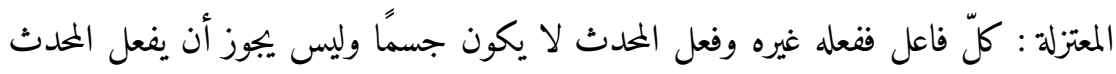
إلاًّ بعض الأعراض.

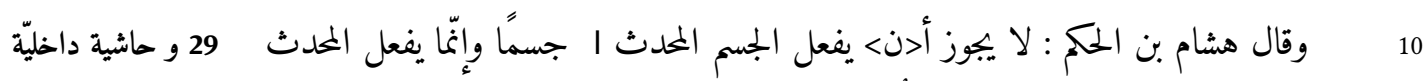

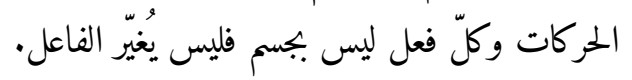

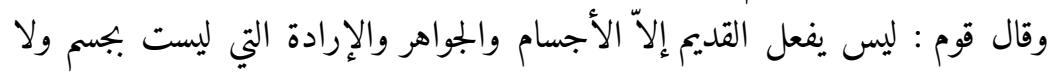
29

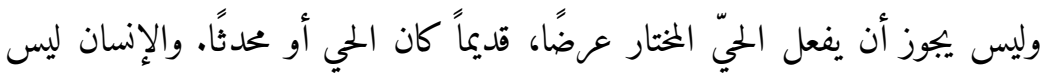

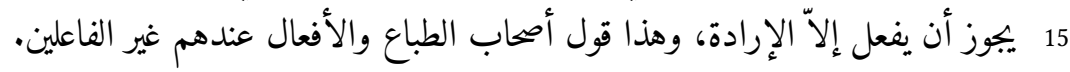

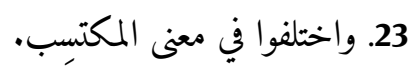

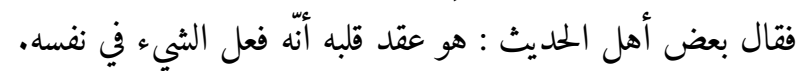

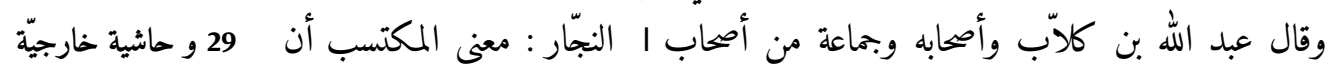
يفعل الفعل الذي في نفسه. وقال الجبّائي : معناه أن يفعل ما بضدّه أو بوفقه. 20

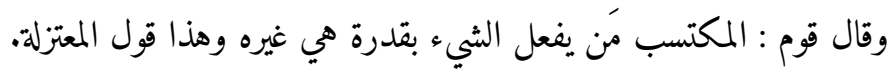




\section{Des actes}

\section{L'acte appartient-il à l'agent ?}

21. a. Selon les théologiens traditionnistes, les disciples d'Ibn Kullāb, les nağğarites, la plupart des mu'tazilites et des chiites, à tout agent appartient un acte et il ne peut y avoir d'agent sans acte.

$b$. Selon al-Așamm, aucun acte n'appartient à l'agent. Ainsi, la prière n'appartient pas à l'orant et ce dernier est orant par lui-même. De même, tout agent autre que Dieu est un agent sans acte.

c. Selon la plupart des dualistes, l'agent agit mais aucun acte ne lui appartient. La plupart des chiites partagent ce point de vue.

\section{De la différence entre l'acte et l'agent}

22. Ils s'opposent au sujet de la quiddité de l'acte ainsi que de sa différence [avec l'agent].

$a$. Les théologiens traditionnistes, 'Abdallāh b. Kullāb et ses disciples, alNağğār et ses partisans, ainsi que la plupart des mu'tazilites disent que l'acte d'un agent est autre que lui, que l'acte d'un [être] adventice ne [saurait] être un corps et qu'un [être] adventice ne peut produire que certains accidents.

$b$. Selon Hišām b. al-Ḥakam, un corps adventice ne peut pas produire [d'autres] corps mais seulement des mouvements. Les actes n'étant pas des corps, ils n'altèrent pas l'agent [qui les produit].

c. Selon certains, l'Éternel ne produit que les corps, les substances et la volonté, laquelle n'est ni corps ni accident.

$d$. Le vivant doté de libre choix, qu'il soit éternel ou adventice, ne peut pas produire d'accidents, et l'homme ne peut produire que sa volonté. C'est la thèse des naturalistes. Selon eux, les actes sont autres que les agents.

\section{De l'acquisition}

23. Ils s'opposent au sujet du sens de l'acquéreur.

a. Selon certains traditionnistes, c'est la conviction interne [à l'agent] d'avoir accompli la chose.

$b$. Selon 'Abdallāh b. Kullāb et ses disciples, ainsi que certains disciples d'alNaǧğār, l'acquéreur signifie celui qui accomplit l'acte qui est en lui-même.

c. Selon al-Ğubbā'î̀, cela signifie qu'il fait soit ce qui s'oppose [à l'acte] soit ce qui s'y conforme.

d. Selon certains, l'acquéreur est celui qui accomplit la chose par une puissance autre que lui. C'est la thèse des mu'tazilites. 
قال متكمّو أصحاب الحديث وعبد الله بن كلاّب وأصحابه و الحسين النجّار وبرغوث ويحيى بن كامل ويحيى بن أصفح وأبو حنيفة وبن الروندي وبشر المريسي و بماعة من الخوارج وغلوّ من المتشيّة : الاستطاعة مع الفعل ومحال وجودها قبل الفعل وهي عرض.

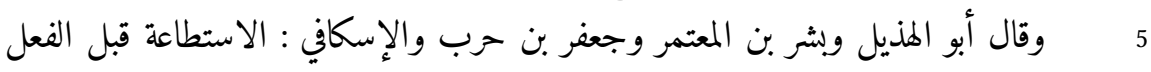

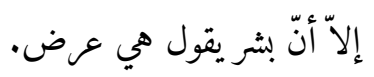

وقال حفص الفرد وصالح قبّة : الاستطاعة قبل وهي في الوقت مشغولة بالفعل، و[تاب] ذلك المعتزلة.

وقال سليمن بن جير : هي قبل الفعل ولا تصلح للفعل إلاّ في وقت وجوده. وقال أبو بكر الأصمّ : ليس للإنسان استطاعة والمستطيع هو السليم الجوارح.

30 ظ حاشية عُليا

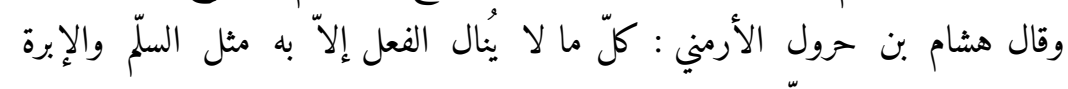
والفأس فهو ا استطاعة وقوّة.

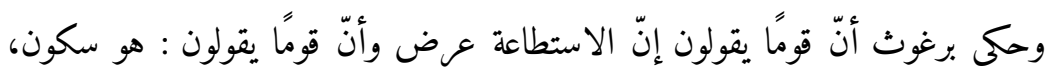
وأنّ قوما يقولون إنّ اعتدال الطبائع هو القدرة. وحكى الخيّاط أنّ هشام بن سالم يقول : هي جسم وهي بعض الإنسان.

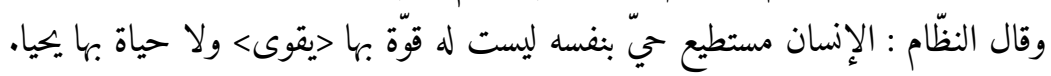

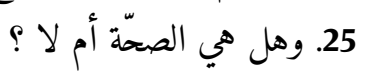

قال أصحاب الحديث و عبد الله بن كلابّ و النجّاريّة و أبو المذيل العلاّف و النجّار

$$
\text { وأصحابه وغيرهم : هي عند الصحّة. }
$$

30 ظ حاشية داخليّة وقال بشر بن المعتمر وجعفر بن ا حرب حئ : الاستطاعة هي الصحّة والسلامة.

30 ظ حاشية سُفلى

$$
\text { وقال هشام بن الحكم وأصحابه : هي عند الصحةّ. }
$$

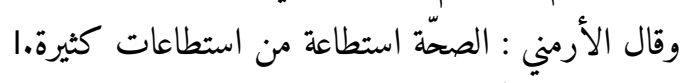

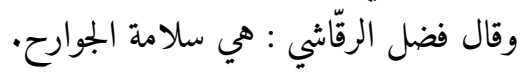

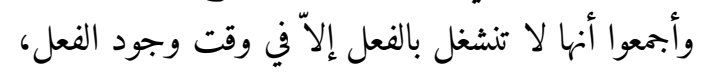




\section{De la capacité}

\section{Définition de la capacité}

24. Les gens s'opposent au sujet de la capacité.

a. Les théologiens traditionnistes, 'Abdallah b. Kullāb et ses disciples, alḤusayn al-Naǧǧār, Burḡūt, Yaḥyā b. Kāmil, Yaḥyā b. Aṣfaḥ, Abū Hanīfa, Ibn alRāwandī, Bišr al-Marīsī, un groupe de hāriǧites et des chiites disent que la capacité est contemporaine à l'acte, qu'il est impossible qu'elle lui soit antérieure et que c'est un accident.

b. Selon Abū al-Hudayl, Bišr b. al-Mu'tamir, Ǧa'far b. Ḥarb et al-Iskāfī, la capacité est antérieure à l'acte. Toutefois, selon Bišr, c'est un accident.

c. Selon Ḥafṣ al-Fard et Șālih Qubba, la capacité est antérieure [à l'acte] et elle est liée à lui au moment de sa production. Les mu'tazilites ont ... cela.

d. Selon Sulaymān b. Ğarīr, elle est antérieure à l'acte et elle ne lui est apte qu'au moment où il existe.

e. Selon Abū Bakr al-Așamm, l'homme n'est pas doté d'une capacité. La [personne] capable est celle dont les membres sont intègres.

f. Selon Hišām b. Harwal al-Armanī, tout ce qui est indispensable à l'obtention de l'acte, comme l'échelle, l'aiguille ou la hache, est capacité et puissance.

g. Au rapport de Burgiūt, certains disent que la capacité est un accident, d'autres qu'elle est repos et d'autres encore que la puissance est la tempérance des humeurs.

h. Au rapport d'al-Ḩayyāṭ, Hišām b. Sālim disait qu'elle est corps et que c'est une partie de l'homme.

i. Selon al-Naz̧āam, l'homme est capable et vivant par lui-même sans être doté d'une puissance par laquelle 〈il peut〉 ou d'une vie par laquelle il vit.

\section{La capacité est-elle la santé ?}

25. [La capacité] est-elle ou non la santé ?

a. Selon les traditionnistes, 'Abdallāh b. Kullāb, les naǧğarites, Abū al-Hudayl al-'Allāf, al-Naǧğar et ses disciples, et d'autres encore, [la capacité] existe avec la santé.

b. Selon Bišr b. al-Mu'tamir et Ğa'far b. Harb, la capacité consiste en la santé et l'intégrité [des membres].

c. Selon Hišām b. al-Ḥakam et ses disciples, elle existe avec la santé.

d. Selon al-Armanī, la santé n'est qu'une capacité parmi tant d'autres.

e. Selon Faḍl al-Raqqāšī, c'est l'intégrité des membres.

$f$. Ils s'accordent tous à dire qu'elle n'est liée à l'acte qu'au moment où il existe, 
إلاّّ العلاّف فإنهّ يفعل بها في الحال الأوّل والفعل لا يوجد إلاّ في الثانية، فخال يفعل عنده غير حال فعل.

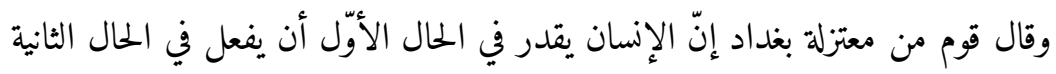

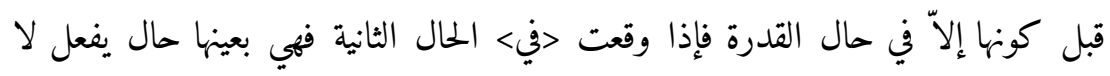
5

31 و حاشية عُليا 26. واختلفوا هل تصلح للطاعة والكفر أم لأحدهما ؟ فقال متكلمّ أهل الحديث وأبو حنيفة وبن الروندي : الإستطاعة تصلح للفعلين جميعًا على البدل. وقال النجّار : ما صلح للكفر لا يصلح للإيمان، وبه قال داود الإصبهاني. 10

27. واختلفوا في الاستطاعة : هي جنس واحد أم أجناس مختلفة ؟ فقال قوم من متكلمي أهل الحديث وغيرهم من المعتزلة وغيرها إنّ أجناسها مختلفة، فا يكون بها الكلام ليست من جنس ما يكون بها المشي. وكذلك القول في الأفعال المختلفة الأجناس.

30 ظ حاشية خارجيّة وقال قوم : كلّها ا جنس واحد، وأحسبهم من المعتزلة. 15

28. حكى أحمد بن الحسن بن أخي زرقان عن مقاتل بن سليمان أنهّ كان يقول إنّ الله 32 ظ ظاشية خارجيّة

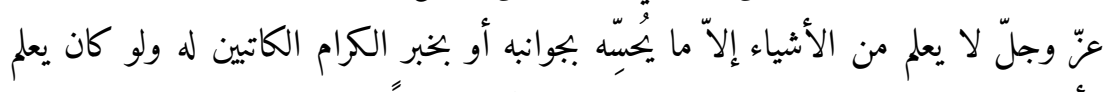
الأشياء من غير هذين الوجهين كان بعثه الكرام الكاتبين عبثًا. 
g. à l'exception d'al-'Allāf [selon] qui [l'homme] agit par [une capacité] dans le premier instant bien que l'acte n'existe que dans le second. En effet, selon lui, l'instant faire est autre que l'instant avoir fait.

h. Selon certains mu'tazilites de Bagdad, l'homme peut, dès le premier instant, accomplir l'acte [qui se produira] au second instant, avant [même] que cet instant ne se produise, sauf dans le cas de la puissance. En effet, lorsque celle-ci se produit dans le second instant, elle est la même que celle qui s'est produite à l'instant faire.

\section{La capacité vaut-elle pour l'obéissance et la mécréance ?}

26. Ils s'opposent quant à savoir si [la capacité] vaut [à la fois] pour l'obéissance et la mécréance ou [seulement] pour l'un des deux [actes].

a. Selon les théologiens traditionnistes, Abū Ḥanīfa et Ibn al-Rāwandī, la capacité vaut indifféremment pour les deux actes.

b. Selon al-Naǧğār, ce qui vaut pour la mécréance ne vaut pas pour la croyance. C’est également la thèse de Dāwūd al-Iṣfahānī.

c. Selon les mu'tazilites, ce qui vaut pour accomplir la foi vaut pour accomplir la mécréance.

\section{La capacité forme-t-elle un même genre?}

27. Ils s'opposent au sujet de la capacité:[forme-t-elle] un même genre ou [plusieurs] genres différents?

a. Selon certains théologiens traditionnistes et certains mu'tazilites et d'autres [groupes], les genres [que forme la capacité] sont différents : [la capacité à l'origine] de la parole n'appartient pas au même genre que celle qui est à l'origine de la marche, et ainsi de suite pour les [autres] actes appartenant à différents genres.

b. Selon certains - je pense qu'il s'agit de mu'tazilites -, toutes [les capacités] appartiennent à un seul genre.

\section{Annexe}

\section{De la Science divine}

28. Au rapport de Aḥmad b. al-Ḥasan b. Ahī Zurqān, Muqātil b. Sulaymān disait que Dieu, exalté soit-Il, ne connaît des choses que ce qu'Il ressent par Ses côtés ou ce que Lui rapportent les anges scribes. Si, en effet, Il connaissait les choses par d'autres moyens, Son envoi des anges scribes serait un acte vain. 
29. قال متكلّمو أهل الحديث وسليمن بن جير وعبد الله بن كلاّب والنجّاريّة وبعض 33 33 و حاشية خارجيّة

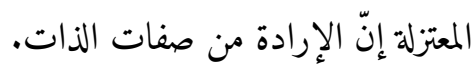
وقال برغوث : الإرادة من الله على ضربين، إرادة أمر فهي صفة خفعل> وإرادة من صفات القدرة وهي صفات في الذات. 5 وقوله، وهذا قول أبي الهذيل العلاّف.

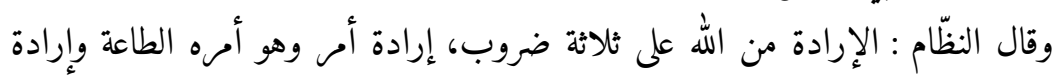

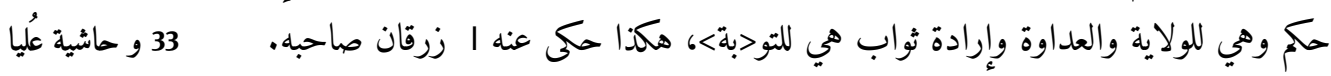

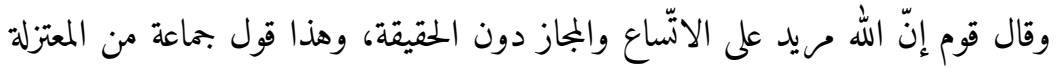

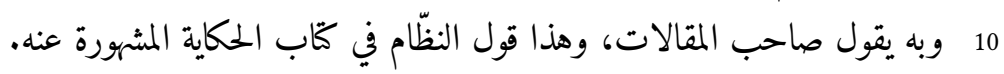

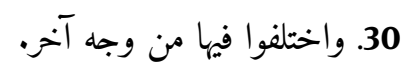

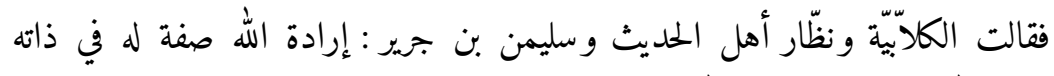
33 و حاشية داخليّة ليست هي الله ولا غيره ا ولا بالله. وقال مَن قال من المعتزلة والنجّاريّة إنّ الإرادة صفة لله في ذاتله الهُ على معنى أنّ الله ميد وليست له إرادة. 15

وقال كلّ مَن زعم أنّ الإرادة من صفات >الذات> ا إنّ الله مريد له إرادة وإرادته 33 و حاشية سُفلى غيره 


\section{De la Volonté divine}

\section{La Volonté de Dieu est-elle un attribut de l'essence ou de l'acte ?}

29. a. Selon les théologiens traditionnistes, Sulaymān b. Ğarīr, 'Abdallāh b. Kullāb, les naǧğārites et certains mu'tazilites, la Volonté est un attribut de l'essence.

b. Selon Burğūt, la Volonté de Dieu est de deux sortes : une Volonté-ordre qui est un attribut 〈de l'acte〉, et une Volonté qui appartient aux attributs de la Science, lesquels sont des attributs de l'essence.

c. Selon certains, la Volonté provenant de Dieu est un attribut de l'acte. C'est un acte créateur qui est [lui-même] incréé, et c'est l'ordre de Dieu et Sa Parole. C'est la thèse d'Abū al-Hudayl al-'Allāf.

d. Selon al-Naẓāām, la Volonté provenant de Dieu est de trois sortes: une Volonté-ordre, à savoir l'ordre de Lui obéir, une Volonté-décret, qui concerne l'amitié et l'inimitié, et une Volonté-rétribution, pour la repentance. C'est ce que rapporte de lui son condisciple Zurqān.

e. Selon certains, Dieu veut au sens large et figuré et non au sens propre. C'est la thèse d'un groupe de mu'tazilites et du doxographe. C'est aussi la thèse d'alNaẓz̄ām consigné dans le livre qui rapporte ses propos célèbres.

\section{Autre question sur la Volonté}

30. Ils s'opposent aussi sur d'autres aspects [de la Volonté].

a. Selon les kullābites, les spéculateurs parmi les traditionnistes et Sulaymān b. Ǧarīr, la Volonté de Dieu est un attribut de Lui dans Son essence, qui n'est ni [identique à] Dieu, ni autre que Dieu, ni en Dieu.

b. Selon quelques mu'tazilites et nağğarites, la Volonté est un attribut de Dieu dans Son essence dans le sens que Dieu est voulant et non qu'Il possède une Volonté.

c. Pour tous ceux selon qui la Volonté est un attribut 〈de l'essence), Dieu est voulant, possède une Volonté et cette Volonté est autre que Lui. 


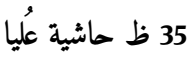

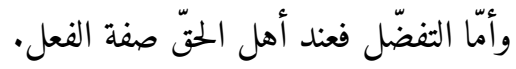

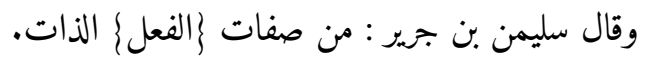

$$
\begin{aligned}
& \text { وهكذا يقول سليمن في الكراهة. } \\
& \text { وقال عبد الله بن كلآب والمعتزلة : من صفات الثرانة الفعل. } \\
& 10 \\
& \text { وبعض أصحاب الحديث توقّف في ذلك. } \\
& \text { والسخط والرضا من ا صفات الذات عند أهل أله الحتّ. }
\end{aligned}
$$

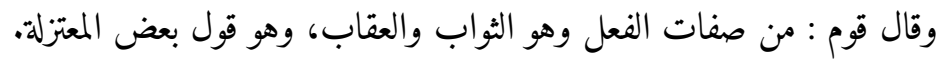

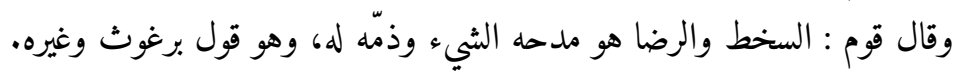

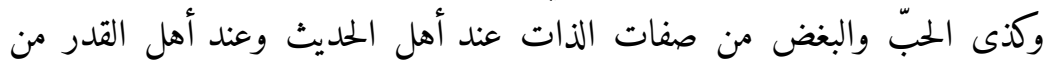

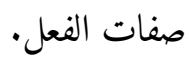

$$
\begin{aligned}
& \text { وكذى الولاية والعداوة من صفات الذات وعند قوم من صفات الفعل. }
\end{aligned}
$$

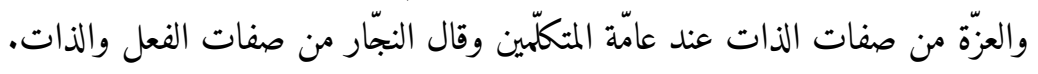

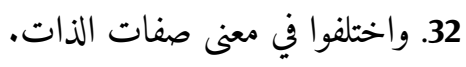$$
35 \text { ظ حاشية داخليّة }
$$

7 الفعل] خطّ فوق الكلمة لحذفها 8 وهكان] وهكنى | يقول] فق السطر 18 والعزّة] العدة 


\section{Attributs de l'essence et attributs de l'acte}

Statut de certains attributs : sont-ils des attributs de l'acte ou de l'essence.

31. Al-sama

a. L'Ouïe est, pour ceux qui sont dans le vrai, un attribut pour appréhender les choses audibles.

b. Selon certains mu'tazilites, tout-audient signifie omniscient, et c'est [également] la thèse des naǧğarites et de l'ensemble des ğahmites.

c. Selon Abū al-Hudayl, l'audient est celui qui écoute les choses audibles. Cela ne désigne pas la Science.

\section{Al-'azama}

d. Quant à la Supériorité, c'est un attribut de l'essence pour les tenants de la vérité.

e. Pour certains mu'tazilites, c'est un attribut de l'acte.

\section{Al-tafaḍ̣ul}

f. La Bienfaisance est, pour ceux qui sont dans le vrai, un attribut de l'acte.

g. Selon Sulaymān b. Ğarīr, c'est un attribut de l'essence.

\section{Al-karāha}

h. Sulaymān soutient la même position au sujet de la Nolonté.

i. Selon 'Abdallāh b. Kullāb et les mu'tazilites, il s'agit d'un attribut de l'acte.

j. Selon les nağğārites, la Nolonté c'est de ne pas vouloir la chose.

$k$. Certains traditionnistes suspendent leur jugement à ce sujet.

\section{Al-saht, al-rị̣a}

l. La Colère et le Consentement sont des attributs de l'essence pour ceux qui sont dans le vrai.

$m$. Selon certains, ce sont des attributs de l'acte, celui de la rétribution et $d u$ châtiment. C'est là la thèse de certains mu'tazilites.

n. Selon d'autres, la Colère et le Consentement sont la louange et le blâme [que Dieu adresse] à autrui. C'est la thèse de Burğūt et d'autres.

\section{Al-hubbb, al-bug்}

o. Il en va de même pour l'Amour et l'Aversion : pour les traditionnistes, ce sont des attributs de l'essence et pour les qadarites, des attributs de l'acte.

\section{Al-walāya, al-'adāwa}

p. Il en va de même pour l'Amitié et l'Inimitié: ce sont des attributs de l'essence, et pour certains, des attributs de l'acte.

\section{Al-'izza}

q. La Force est l'un des attributs de l'essence pour l'ensemble des théologiens, et selon al-Naǧğār, c'est un attribut de l'acte et de l'essence.

\section{Définition des attributs de l'acte et de l'essence}

32. Ils s'opposent quant à la signification des attributs de l'essence. 


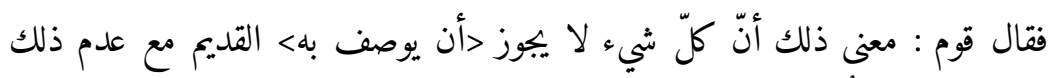

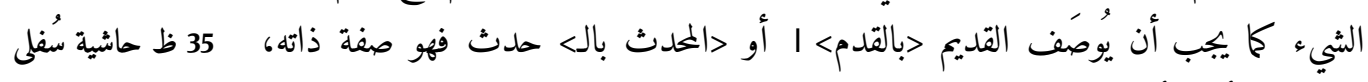

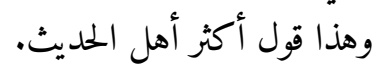

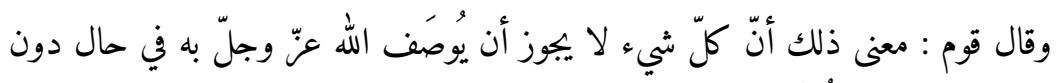

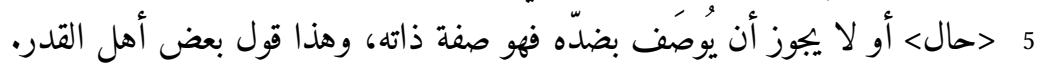

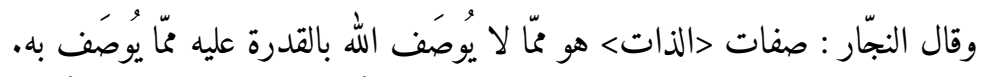

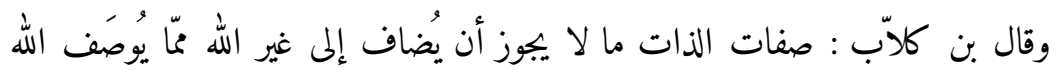


a. Selon certains, toute chose qui, lorsqu'elle n'existe pas, ne saurait 〈qualifier) l'Éternel, à la manière dont 〈l'Éternité〉 doit qualifier l'Éternel et l'adventicité 〈l'adventice〉, est un attribut de l'essence. C'est la thèse de la plupart des traditionnistes.

b. Selon certains, tout ce qui ne saurait servir à qualifier Dieu, exalté soit-Il, à un moment à l'exclusion 〈d'un autre〉 ou tout ce dont le contraire ne saurait servir à qualifier Dieu est un attribut de l'essence. C'est la thèse de certains qadarites.

c. Selon al-Nağğăr, parmi [les attributs] qui Le qualifient, les attributs 〈de l'essence) sont ceux dont [Dieu] n'est pas qualifié comme ayant la puissance d'accomplir.

d. Selon Ibn Kullāb, parmi [les attributs] qui qualifient Dieu, les attributs de l'essence sont ceux qui ne peuvent être attribués à d'autres qu'à Lui. 
37 و حاشية سُفلى

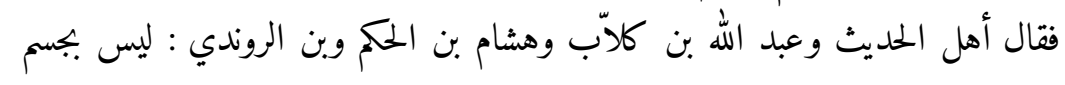
ولا وض ولا جوهر.

وقال الجاحظ والأصمّ والنظّام وغيرهم : هو جسم.

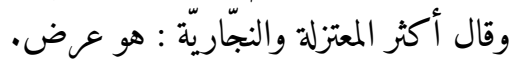
5

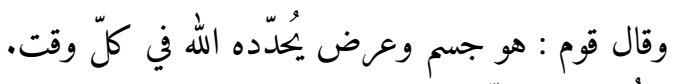

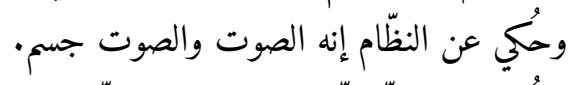

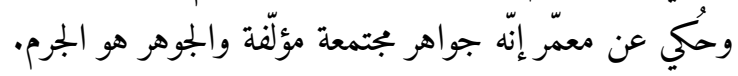

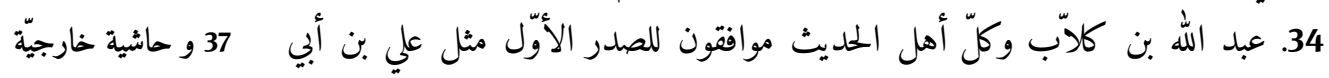

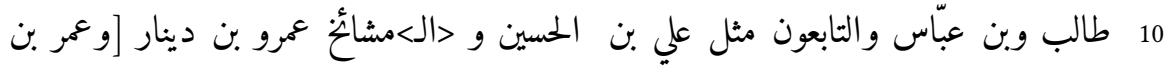

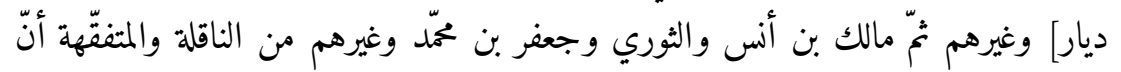

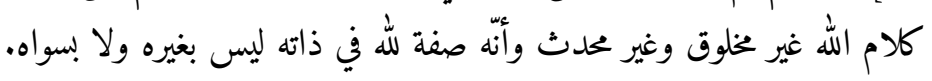

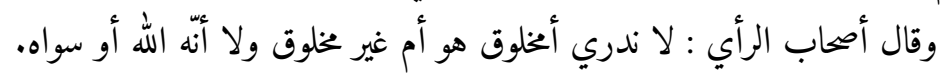

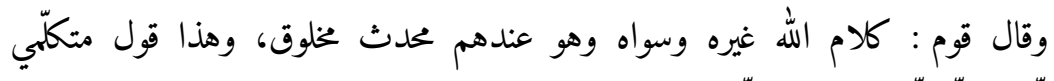
15 القدريّة والنجّاريّة وباقي الجهميّة.

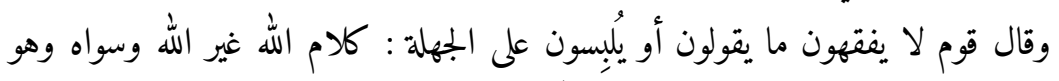
37 و حاشية عُيا

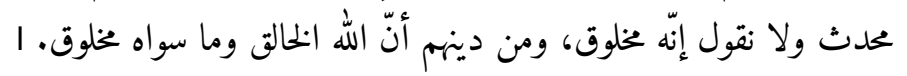

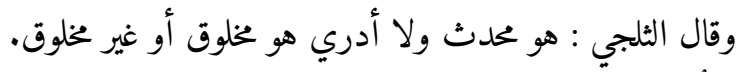

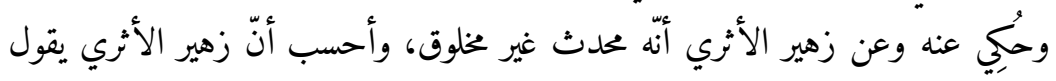
20 حدث وخلق غير مخلوق.

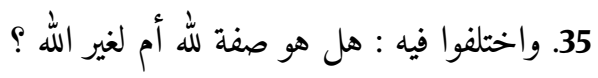

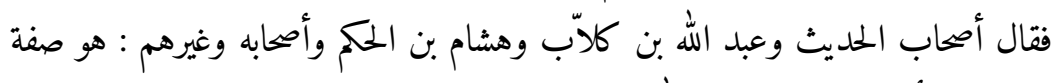
37 لله وليس يجوز أن يكون صفة لغير الله. 


\section{De la Parole de Dieu}

\section{Est-elle corps ou accident?}

33. Ils s'opposent au sujet de [la Parole de Dieu] : est-elle un corps ou un accident?

a. Selon les traditionnistes, 'Abdallāh b. Kullāb, Hišām b. al-Ḥakam et Ibn alRāwandī, ce n'est ni un corps, ni un accident, ni une substance.

b. Selon al-Ǧāḥiz, al-Aṣamm, al-Naẓāām et d'autres, c'est un corps.

c. Selon la plupart des mu'tazilites et des naǧğārites, c'est un accident.

d. Selon certains, c'est un corps et un accident que Dieu détermine à chaque instant.

e. On rapporte d'al-Naz̧āām qu'il s'agit d'un son ; or le son est un corps.

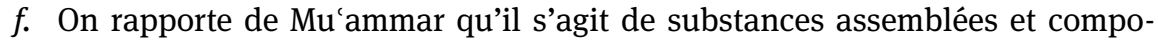
sées ; or la substance est un corps (ǧirm).

\section{Est-elle ou non créée?}

34. $a$. 'Abdallāh b. Kullāb et tous les traditionnistes sont en accord avec la première génération comme 'Alī b. Abī Țālib et Ibn 'Abbās, ainsi qu'avec les Suivants comme 'Alī b. al-Ḥusayn, les docteurs [comme] 'Amr b. Dīnār et d'autres, et avec Mālik b. Anas, al-Tawrī, Ğa'far b. Muhamammad et d'autres rapporteurs et savants que la Parole de Dieu est incréée, qu'elle n'est pas adventice, que c'est un attribut de Dieu dans Son essence, qui n'est ni autre que Dieu ni différent de Lui.

$b$. Les tenants de l'opinion personnelle disent : «Nous ne savons pas si elle est créée ou incréée ni si elle est Dieu ou autre que Lui. »

c. Selon certains, la Parole de Dieu est autre que Dieu et elle est selon eux adventice et créée. C'est l'opinion des théologiens qadarites, naǧğārites et autres ğahmites.

d. Certains, ne comprenant même pas ce qu'ils disent ou voulant induire les ignorants en erreur, disent : " La Parole de Dieu est autre que Dieu et elle est adventice, mais nous ne disons pas qu'elle est créée », alors que selon leur dogme, seul Dieu est créateur et le reste est créé.

e. Al-Talğī dit : «Elle est adventice et je ne sais pas si elle est créée ou incréée.»

$f$. On rapporte de lui et de Zuhayr al-Atarai qu'elle est adventice et incréée. Il me semble que selon Zuhayr, c'est un événement et une création incréée.

\section{Est-elle un attribut de Dieu ?}

35. Ils s'opposent au sujet de [la Parole] : est-elle un attribut de Dieu ou d'autre chose que Dieu?

a. Selon les traditionnistes, 'Abdallāh b. Kullāb, Hišām b. al-Ḥakam et ses disciples, ainsi que d'autres, [la Parole] est un attribut de Dieu et elle ne peut être attribut d'autre chose que Dieu. 
وقالت المعتزلة وبعض النجّاريّة : كلّ كلام لله وصف به نفسه فهو صفة لله وما

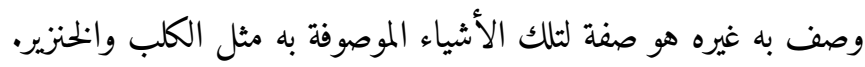

37 ظ حاشية سُفلى

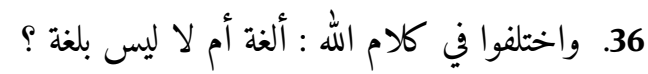

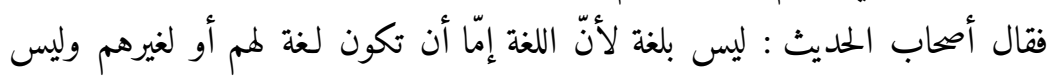
5

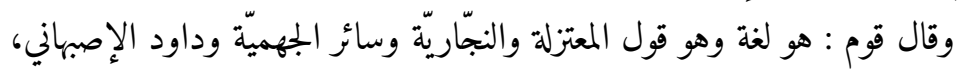
وهو عند داود مختلف غير مخلوق وصفة ذاتيّة.

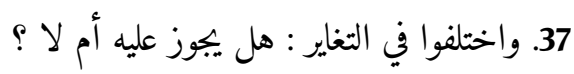

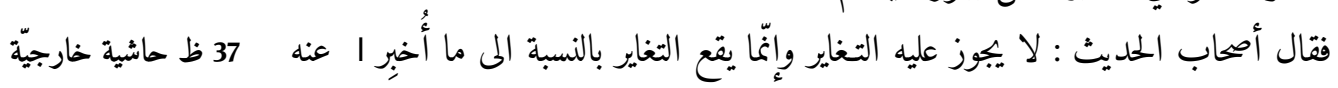
10 وقال متكلّمو المعتزلة و النجّاريّة وسائر الجهميّة : هو متغاير مختلف لأنه أشياء محدثة

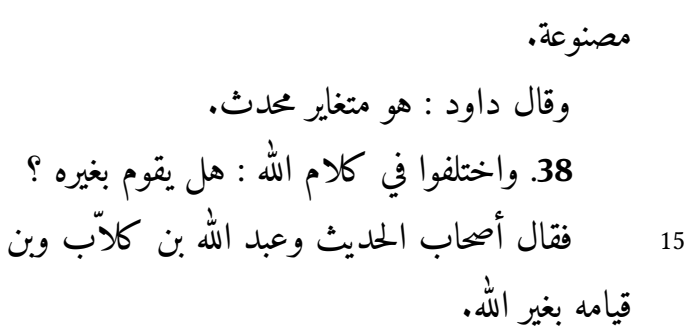

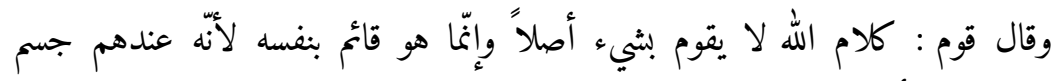
والأجسام تقوم بأنفسها.

وقال قوم : هو قائم ا بالجسم الذي يحلّه، وهؤلاء أصحاب الأعراض تمّن يقول 37 ظ حاشية عُليا 20

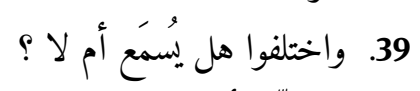

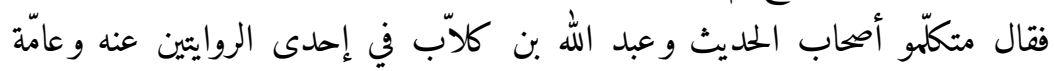
المعتزلة والنجّار والمتشيّة إنّ كلام الله مسموع على الملى الحقيقة. 
b. Selon les mu'tazilites et quelques naǧğārites, toute parole divine dont Il s'est qualifiée est un attribut de Lui, mais tout ce dont Il a qualifié les autres choses est un attribut de ces choses, comme le chien et le porc.

\section{Est-elle une langue?}

36. Ils s'opposent au sujet de la Parole de Dieu : est-elle ou non une langue?

a. Selon les traditionnistes, elle n'est pas une langue car les langues appartiennent à certains [groupes] à l'exclusion d'autres, alors que la Parole de Dieu n'est une langue pour personne [en particulier] mais peut être lue dans les différentes langues.

b. Selon certains, c'est une langue. C'est la thèse des mu'tazilites, des nağğārites et de l'ensemble des ğahmites, ainsi que de Dāwūd al-Iṣfahānī.

c. [Cependant], selon Dāwūd, elle est variée (muhtalif), incréée et c'est un attribut de l'essence.

\section{Peut-elle se différencier?}

37. Ils s'opposent quant à savoir si elle peut se différencier en elle-même (tag்āyur).

a. Selon les traditionnistes, elle ne peut se différencier en elle-même. Seules les choses qui peuvent faire l'objet d'un énoncé informatif, comme le vin ou le feu, se différencient les unes des autres.

b. Selon les théologiens mu'tazilites, naǧğārites, et l'ensemble des ğahmites, elle se différencie en elle-même et varie parce qu'elle consiste en choses adventices et fabriquées.

c. Selon Dāwūd, elle se différencie en elle-même et elle est adventice.

\section{Subsiste-t-elle en autre chose que Lui ?}

38. Ils s'opposent au sujet de la Parole de Dieu: subsiste-t-elle en autre chose que [Dieu] ?

a. Selon les traditionnistes, 'Abdallāh b. Kullāb, Ibn al-Rāwandī et d'autres, elle subsiste en Dieu et ne peut subsister en autre chose que Lui.

$b$. Selon certains, la Parole de Dieu ne subsiste en rien ; elle subsiste [uniquement] en elle-même. En effet, selon eux, elle est un corps et les corps subsistent en eux-mêmes.

c. Selon certains, elle subsiste dans le corps où elle inhère. Ceux-là sont les tenants des accidents qui affirment l'inhérence du Coran.

\section{Est-elle ou non audible?}

39. Ils s'opposent quant à savoir si elle est ou non audible.

a. Selon les théologiens traditionnistes, 'Abdallāh b. Kullāb (d'après l'une des deux versions de sa thèse), l'ensemble des mu'tazilites, al-Nağğār et les chiites, la Parole de Dieu est audible au sens propre. 

38 و حاشية خارجيّة

وقال بن الروندي وأبو عيسى الورّاق إنّ كلام الله لا يُسمَع على الحقيقة.

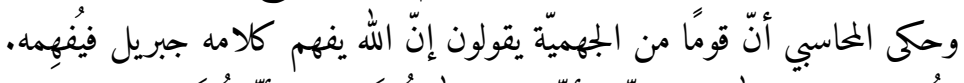

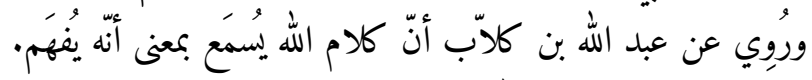

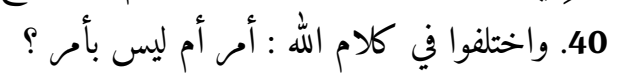
5

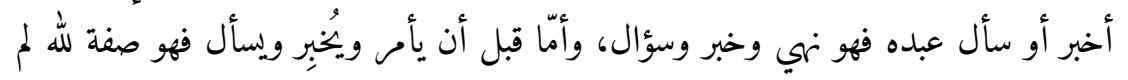

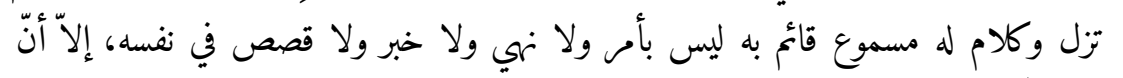
عبد الله بن كلآب لا يقول إنّه مسموع كما يقول الباقون.

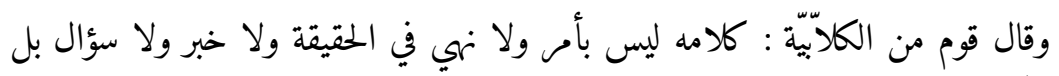

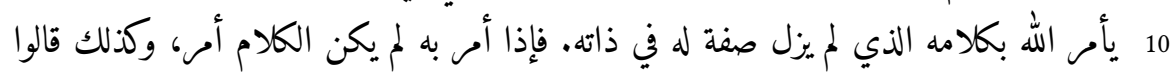
38 ا في النهي وغيره من أقسام الكلام.

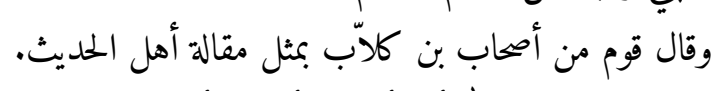

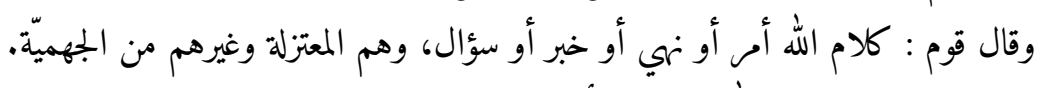

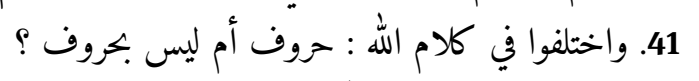

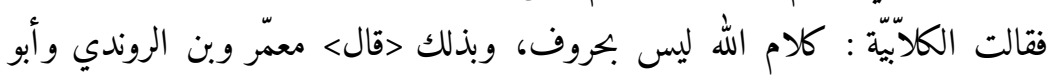
15 عيسى الورّاق.

وقال قوم : كلام الله حروف مؤلّة، ا وهذا قول بعض المعتزلة والنجّاريّة وأكثر 38 و حاشية داخليّة

حركة. وقال آخرون : حركة قائمة في الصوت والحركة عند هؤلاء >عرض> فيما 38 و حاشية سُفلى

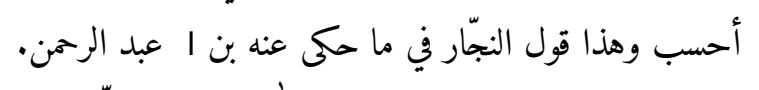
20

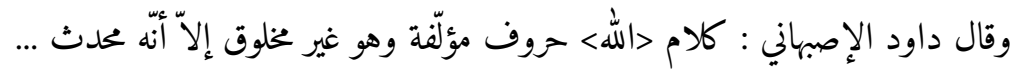

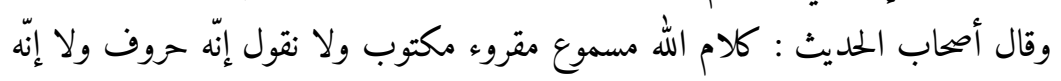

$$
\text { ليس بحروفّ. }
$$

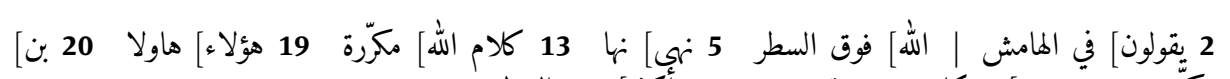
مكرّة 21 محدثث] + كلمتين غير مقروءتين 25 وأكثر] فوق السطر 
b. Selon Ibn al-Rāwandī et Abū 'Īsā al-Warrāq, la Parole de Dieu n'est pas audible au sens propre.

c. Au rapport d'al-Muhāāsibī, certains ğahmites affirment que Gabriel comprend la Parole de Dieu et la transmet.

d. On rapporte d'Ibn Kullāb que la Parole de Dieu est audible dans le sens de compréhensible.

\section{Est-elle ou non un ordre?}

40. Ils s'opposent au sujet de la Parole de Dieu : est-elle ou non un ordre?

a. Selon les traditionnistes et 'Abdallāh b. Kullāb, lorsque Dieu ordonne par Sa Parole, elle est ordre, et lorsqu'll défend, informe ou questionne l'homme, elle est défense, information et question. Cependant, avant qu'll n'ordonne, n'informe ou ne questionne, c'est un attribut de Dieu qui n'a pas cessé d'être et une Parole audible qui subsiste en Lui et qui n'est en soi ni ordre, ni défense, ni information, ni récits. Toutefois, Ibn Kullāb n'utilise pas [le terme] « audible » dans le sens où l'entendent les autres.

b. Selon certains kullābites, Sa Parole n'est ni ordre ni défense au sens propre, ni information ni question. Dieu ordonne par Sa Parole qui n'a pas cessé d'être un attribut de Son essence (șifa lahu fì dātihi). Ainsi, lorsqu'Il ordonne par Sa Parole, celle-ci ne devient pas ordre [pour autant] ; et ils ont étendu cela à la défense et aux autres parties du discours.

c. D'autres disciples d'Ibn Kullāb partageaient la thèse des traditionnistes.

d. Selon certains - la Parole de Dieu est ordre, défense, information ou question. Ceux-là sont les mu'tazilites et autres ğahmites.

\section{Consiste-t-elle ou non en lettres?}

41. Ils s'opposent au sujet de la Parole de Dieu: consiste-t-elle ou non en lettres?

a. Selon les kullābites, la Parole de Dieu ne consiste pas en lettres. Il en va de même pour $\mathrm{Mu}$ 'ammar, Ibn al-Rāwandī et Abū 'Īsā al-Warrāq.

$b$. Selon certains, la Parole de Dieu consiste en lettres composées. C'est la thèse de certains mu'tazilites, des nağğarites et de la plupart des ğahmites.

Mouvement

c. Selon d'autres, c'est un mouvement qui subsiste dans la voix, et il me semble que pour ceux-là, le mouvement est 〈un accident〉. C'est la thèse d'al-Nağğār au rapport de Ibn 'Abd al-Raḥmān.

d. Selon Dāwūd al-Isfahānī, la Parole 〈de Dieu〉 consiste en lettres composées. Elle est incréée mais adventice ...

e. Les traditionnistes disent : " La Parole de Dieu est audible, lisible, scriptible, et nous ne disons ni qu'elle consiste en lettres ni qu'elle ne consiste pas en lettres. »

$f$. Selon les kullābites et d'autres, la Parole 〈de Dieu〉 n'est pas un son.

g. Selon la majorité des nağğarites et d'autres groupes, c'est un son. 
38 ظ حاشية خارجيّة

وقال النظّام : هو الصوت المؤلّف المقّطع.

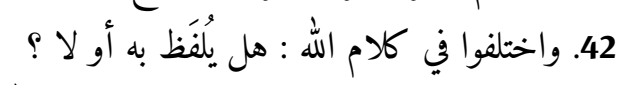

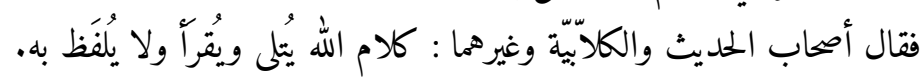
وقال قوم : كلام الله يُلفظظ به، وهو قول داود الإصبهاني والحسين الكرابيسي. 5

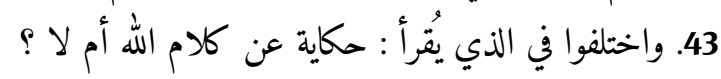

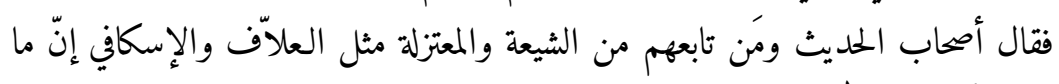
نسمعه ونقرأه كلام الله على الحقيقة دون المجاز.

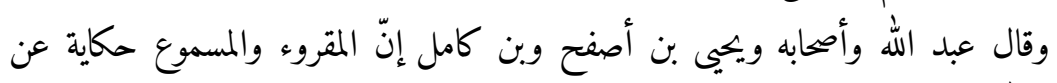
10 
h. Selon al-Naẓāām, c'est le son composé et articulé.

\section{Est-elle ou non prononçable?}

42. Ils s'opposent au sujet de la Parole de Dieu: est-elle ou non prononçable?

a. Selon les traditionnistes, les kullābites et d'autres, la Parole de Dieu peut être récitée et lue mais elle n'est pas prononçable.

b. Selon d'autres, elle est prononçable. C'est la thèse de Dāwūd al-Ișfahānī et d'al-Ḥusayn al-Karābīsī.

c. Selon certains, qui imitent les traditionnistes, lire la Parole de Dieu, c'est la prononcer.

\section{La lecture est-elle une citation de la Parole de Dieu ?}

43. Ils s'opposent au sujet de ce qu'on lit : est-ce ou non une citation de la Parole de Dieu?

a. Selon les traditionnistes, les chiites et les mu'tazilites qui les ont suivis en cela, comme al-'Allāf et al-Iskāfī, ce que nous entendons et lisons, c'est la Parole de Dieu au sens propre et non au sens figuré.

b. Selon 'Abdallāh [b. Kullāb] et ses disciples, Yahyyā b. Așfaḥ et [Yaḥyā] b. Kāmil, on lit et on entend une citation de la Parole de Dieu. La plupart des théologiens sont de cet avis. 


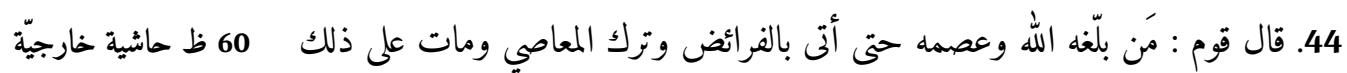

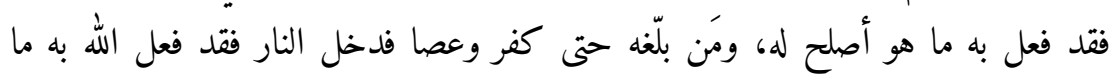

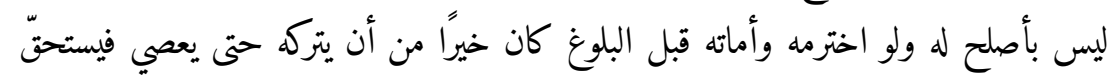

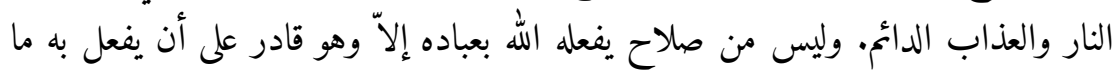

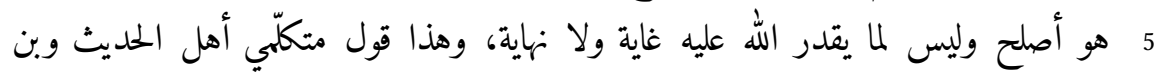

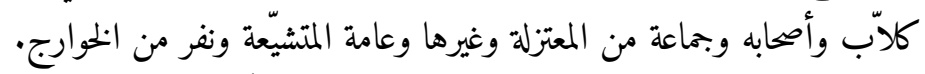

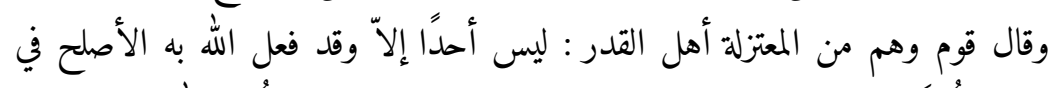

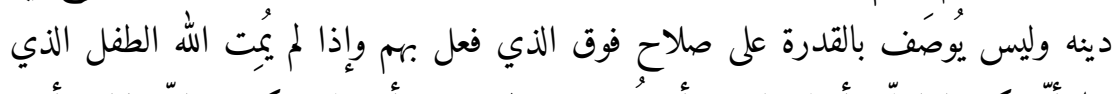

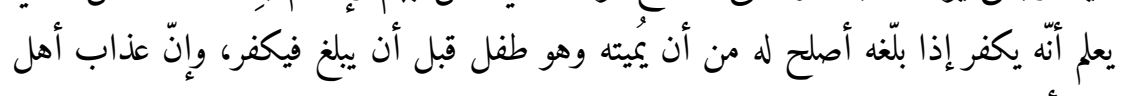
60 10 النار أصلح ا لهم من إخراجهم من النار.

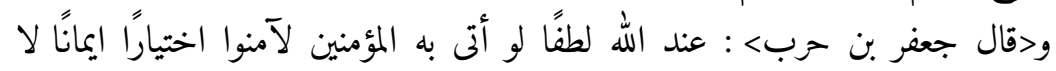

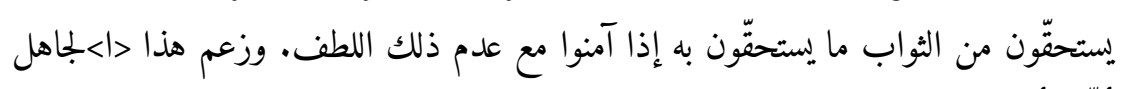

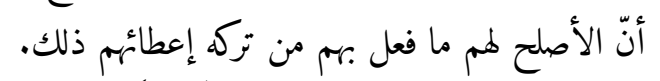

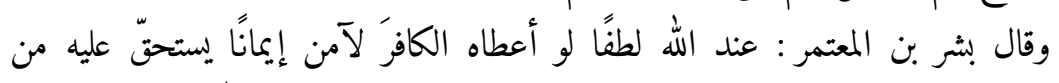

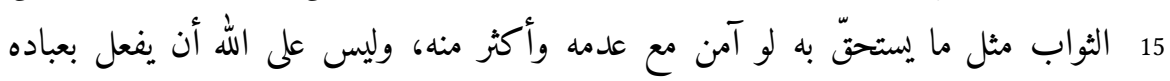

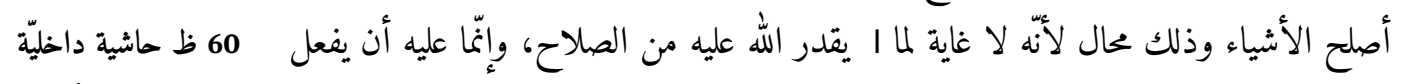
60 كهم ما هو صلاح ا في دينهم.

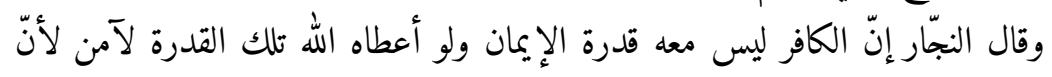

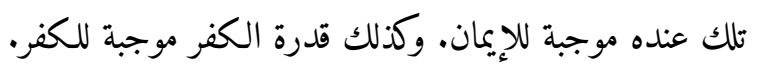

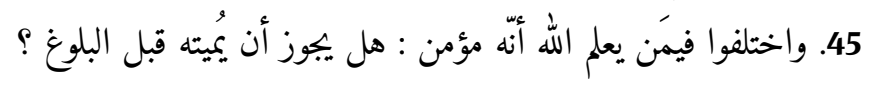




\section{De la Justice divine}

\section{La grâce et l'avantage maximal}

44. a. Selon certains, lorsque Dieu laisse [un homme] atteindre la majorité et qu'Il le protège [de toute tentation], [le laissant ainsi] accomplir ses devoirs, omettre les péchés puis mourir dans cet état, Il lui aura octroyé l'avantage maximal. [En revanche], lorsqu'Il le laisse atteindre la majorité et que [l'homme] mécroit, désobéit et finit en enfer, Il ne lui aura pas octroyé l'avantage maximal. [Dans ce cas], il serait préférable que [Dieu] le fasse périr et le laisse mourir avant la majorité, plutôt que de le laisser mécroire de sorte à mériter [de séjourner] en enfer et [de subir] un tourment perpétuel. Il n'est aucun avantage octroyé par Dieu à Ses serviteurs qu'Il ne puisse surpasser par un plus grand avantage, et il n'y a nulle fin ni limite au pouvoir de Dieu. C'est la thèse des théologiens traditionnistes, d'Ibn Kullāb et de ses disciples, d'un groupe de mu'tazilites et d'autres personnes, de l'ensemble des chiites et d'un groupe de hāriǧites.

b. Selon d'autres - et ce sont les mu'tazilites tenants du qadar -, il n'est personne à qui Dieu n'ait octroyé l'avantage maximal en ce qui concerne sa religion. On ne peut attribuer à [Dieu] la puissance d'[octroyer] un avantage supérieur à celui qu'Il a octroyé [aux hommes]. Et si Dieu ne fait pas mourir un enfant dont Il sait qu'il mécroirait s'Il le laissait atteindre la majorité, [c'est que] cela est plus avantageux pour [l'enfant] que de mourir jeune, avant d'atteindre la majorité et de mécroire. [De même], les tourments des hommes [qui séjournent] en Enfer leur sont plus avantageux qu'une sortie de l'Enfer.

c. 〈Selon Ğa'far b. Harb〉, Dieu détient une grâce telle que, s’ll l'accordait aux croyants, ils croiraient volontairement d'une foi qui ne leur vaudrait pas une récompense égale à celle qu'ils auraient méritée s'ils avaient cru sans cette grâce. Cet ignorant prétend aussi que l'avantage maximal pour eux, c'est ce que [Dieu] leur a fait en omettant de leur donner cela.

d. Selon Bišr b. al-Mu'tamir, Dieu détient une grâce telle que, s'Il l'accordait au mécréant, il croirait d'une foi qui lui vaudrait une récompense égale, voire supérieure, à celle qu'il aurait méritée s’il avait cru sans cette grâce. Dieu n'est pas tenu d'octroyer à Ses serviteurs les choses les plus avantageuses ; cela est [même] impossible, car il n'y a pas de limite au pouvoir de Dieu en matière d'avantages. Il est uniquement tenu de leur octroyer ce qui est avantageux pour leur religion.

$e$. Selon al-Naǧğār, le mécréant ne détient pas la puissance de croire, et si Dieu la lui accordait, il croirait, car celle-ci, venant de Dieu, entraîne nécessairement la foi. De même, la puissance de mécroire entraîne nécessairement la mécréance.

\section{Dieu peut-Il faire mourir avant la majorité celui dont Il sait qu'il croira ?}

45. Ils s'opposent au sujet de celui dont Dieu sait qu'il croira : peut-Il le faire mourir avant sa majorité ? 
فقال قوم منهم نظّار أهل الحديث والكلابِّيّة والنجّاريّة وغيرهم إنّ ذلك جائز.

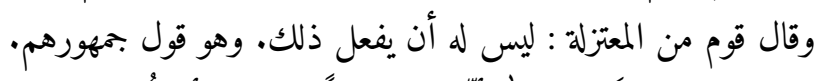

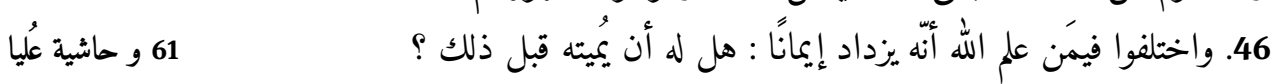

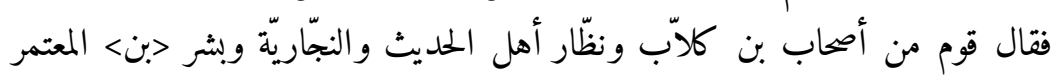
5 و وعامّة الشيعة وأكثر أهل النظر إنّ ذلك جائز.

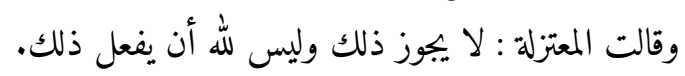

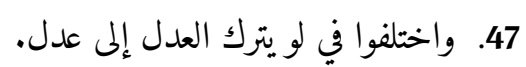

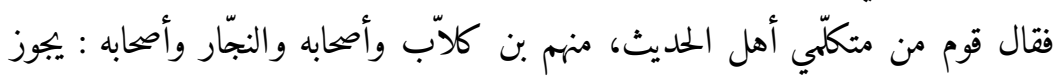
ذلك ويجوز ترك صلاح إلى صلاح مثله. وقال عبّاد إنّ ذلك غير جائز. 10

61 وقال ا قوم من المعتزلة : يجوز ذلك.

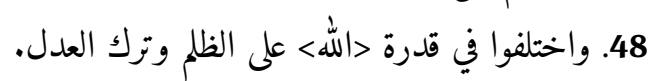

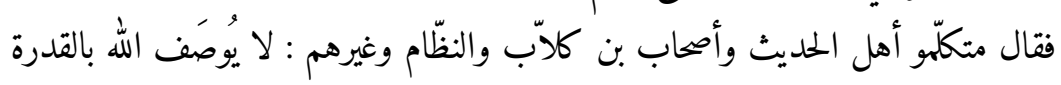
على أن يجور ويظلم. 15

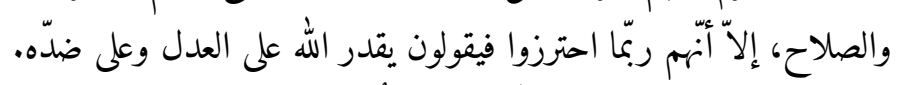

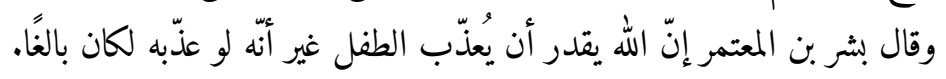

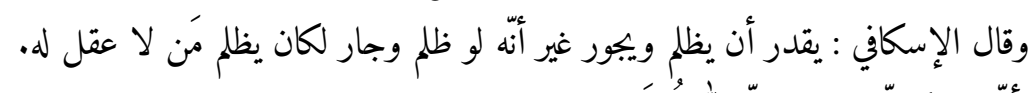

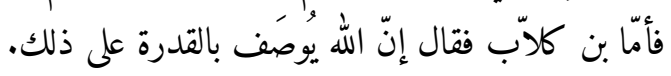

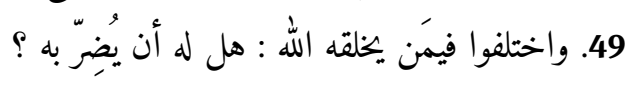


a. Selon certains, comme les spéculateurs traditionnistes, les kullābites et les nağğārites, cela est possible.

b. Selon certains mu'tazilites - et c'est leur opinion majoritaire -, Il ne peut faire une chose pareille.

\section{Celui dont la foi augmentera peut-il mourir?}

46. Ils s'opposent au sujet de celui dont Dieu sait que la foi augmentera : peut-Il le faire mourir avant cela?

a. Selon certains disciples d'Ibn Kullāb, les spéculateurs traditionnistes, les naǧğārites, Bišr $\langle\mathrm{b}$. $\rangle$ al-Mu'tamir, l'ensemble des chiites et la plupart des spéculateurs, cela est possible.

b. Selon les mu'tazilites, cela n'est pas possible et Dieu ne peut pas faire cela.

\section{Dieu peut-Il omettre une justice en vue d'une autre?}

47. Ils s'opposent au sujet de la possibilité [pour Dieu] d'omettre une justice en vue d'une autre.

a. Selon certains théologiens traditionnistes, dont Ibn Kullāb et ses disciples, et [selon] al-Naǧğār et ses disciples, cela est possible tout comme il est possible d'omettre un avantage en vue d'un autre avantage qui lui est équivalent.

b. Selon 'Abbād, cela n'est pas possible.

c. Selon certains mu'tazilites, cela est possible.

\section{Dieu peut-Il commettre l'injustice?}

48. Ils s'opposent au sujet de la puissance 〈divine〉 de commettre l'injustice et d'omettre la justice.

a. Selon les théologiens parmi les traditionnistes, les disciples d'Ibn Kullāb, alNaẓzām et d'autres, on ne peut attribuer à Dieu la puissance de commettre l'injustice et l'iniquité.

b. Selon certains, dont Abū al-Hudayl et d'autres, Dieu peut commettre l'injustice et l'iniquité tout comme Il accomplit la justice et ce qui est avantageux, mais sans doute évitent-ils [d'affirmer cela] et parlent-ils [plutôt] de la puissance de Dieu à commettre la justice et son contraire.

c. Selon Bišr b. al-Mu'tamir, Dieu peut tourmenter un enfant, mais s'll le faisait [réellement], [l'enfant serait en réalité] une personne majeure.

d. Selon al-Iskāfī, Il peut commettre l'injustice et l'iniquité mais s'll le faisait, ce serait à l'égard d'une [personne] dépourvue de raison.

e. Quant à Ibn Kullāb, on peut selon lui attribuer cette puissance à Dieu.

\section{Peut-Il nuire à Sa propre créature ?}

49. Ils s'opposent quant à savoir si Dieu peut nuire à ce qu'Il a créé. 
فقال قوم من نظّار أهل الحديث وجماعة من النجّاريّة ا فيما حكى بن الروندي إنّ الله 61 و حاشية سُفلى

$$
\text { لا يُضرّ أحدًا في دينه. }
$$

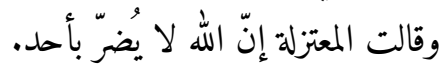

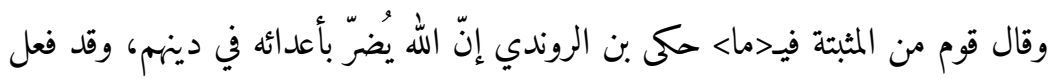

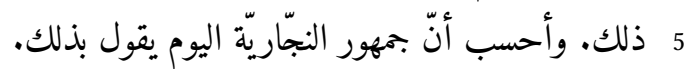

$$
\text { 50. واختلفوا في دوام إيلام مَن لا جرم لها له. }
$$

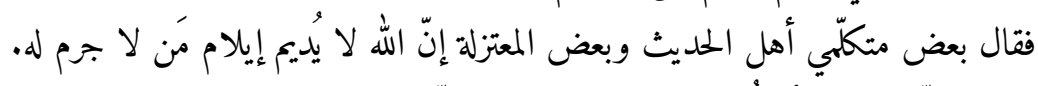

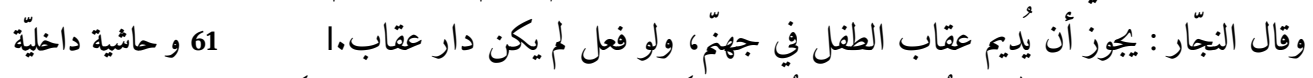

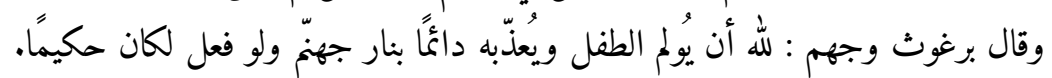

61 51. اختلف الناس في الآلام. 10

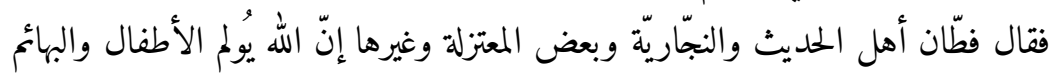
من غير ذنب ولا جناية وهو حكيم في ذلك.

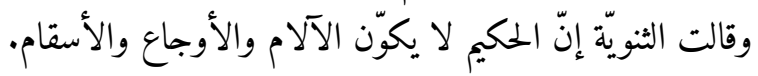

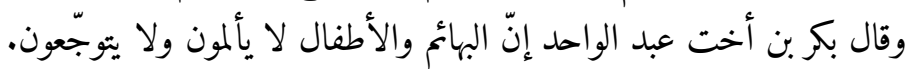

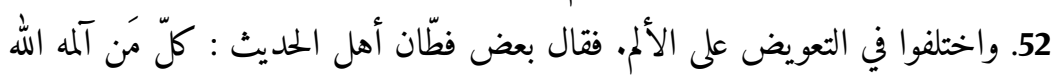

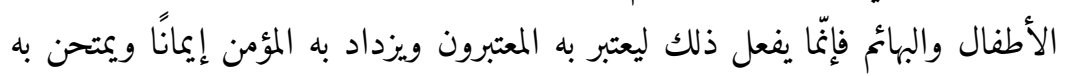

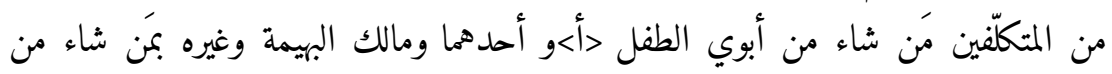

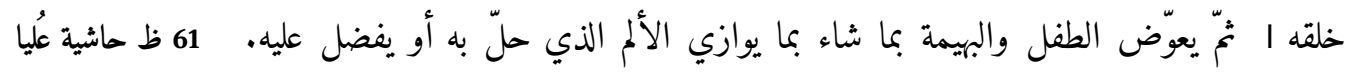

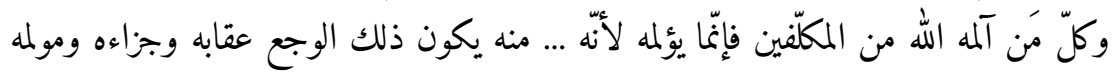
20

13 الثنويّة] قراءة ظنّيّة 15 أهل] مكرّرة 16 إيمانًا] امانا 17 أحدهما] قراءة ظنّية 19 لأنهّ] + كلمة غير مقروءة 20 لخبث] قراءة ظنيّة 
a. Au rapport d'Ibn al-Rāwandī, selon certains spéculateurs parmi les traditionnistes et un groupe de nağğārites, Dieu ne nuit à personne en ce qui concerne sa religion.

b. Selon les mu'tazilites, Dieu ne nuit à personne.

c. Selon certains affirmationnistes, au rapport d'Ibn al-Rāwandī, Dieu nuit à Ses ennemis dans leur religion et Il l'a déjà fait. Je pense que, de nos jours, la majorité des nağğārites sont de cet avis.

\section{Les souffrances imméritées sont-elles pérennes?}

50. Ils s'opposent au sujet de la pérennité des souffrances de ceux qui n'ont commis aucun crime.

a. Selon certains théologiens traditionnistes et certains mu'tazilites, Dieu n'éternise pas les souffrances de celui qui n'a pas commis de crime.

b. Selon al-Naǧğār, Il lui est possible d'éterniser le châtiment d'un enfant en Enfer, mais s'Il le faisait, l'Enfer ne serait plus la demeure du châtiment.

c. Selon Burgūut et Ğahm, Dieu peut châtier à jamais un enfant et lui infliger des souffrances en Enfer, et s'Il le faisait, Il serait sage.

\section{Questions au sujet des souffrances}

51. Les gens s'opposent au sujet des souffrances.

a. Selon les traditionnistes les plus perspicaces, et selon les nağğārites, les mu'tazilites et d'autres, Dieu fait souffrir les enfants et les bêtes qui n'ont commis aucune faute ni aucun crime et, [même] en cela, Il fait preuve de sagesse.

$b$. Selon les dualistes, le Sage ne crée pas les souffrances, les maux ni les maladies.

c. Selon Bakr b. Uht 'Abd al-Wāhịid, ni les bêtes ni les enfants n'éprouvent la souffrance.

\section{La compensation des souffrances}

52. Ils s'opposent au sujet de la compensation des souffrances.

a. Selon certains traditionnistes perspicaces, Dieu n'inflige de souffrances aux enfants et aux bêtes que pour servir de leçon aux hommes, pour augmenter la foi des croyants ou pour éprouver, parmi ceux à qui Il impose obligation, les deux parents de l'enfant, ou l'un des deux, ou le propriétaire de la bête, ou quiconque d'autre à Sa guise. Ensuite, Il compense [les souffrances de] l'enfant et de la bête par ce qu'll veut, que ce soit par l'équivalent [en félicité] de la souffrance endurée ou par une quantité [de félicité] supérieure. Dieu n'inflige de souffrances aux hommes que ... Cette douleur est leur châtiment et leur salaire. Il lui inflige une souffrance en raison d'une malice [de l'homme] ou pour le mettre à l'épreuve. La plupart des mu'tazilites soutiennent une thèse similaire.

b. Selon certains d'entre eux, [Dieu] inflige des souffrances aux hommes afin qu'ils accèdent grâce à cela à des niveaux [supérieurs] du Paradis. Dieu ne saurait les 


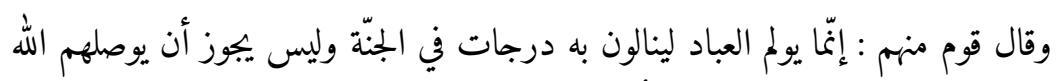

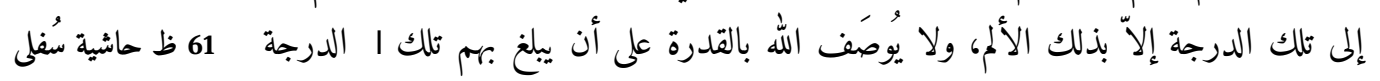
وقال عبّاد إنّ نعيم الأطفال ليس بعوض والأطفال والبهائم لا يعوضون على الأمل الذي إلاّ بذلك الألم.

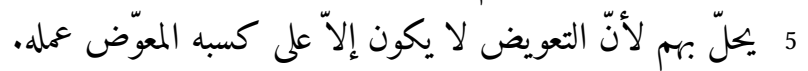

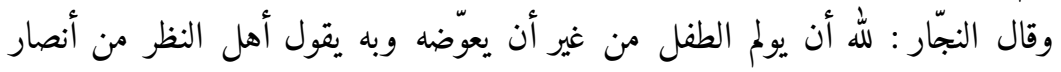
الحديث. 
conduire à de tels niveaux sans cette souffrance et on ne peut dire qu'll a puissance à les faire accéder à ces niveaux par autre chose que par cette souffrance.

c. Selon 'Abbād, le Paradis pour les enfants n'est pas une compensation. [En effet], les souffrances que les enfants et les bêtes endurent ne sont pas compensées car il n'y a compensation que lorsque la [personne] compensée recueille [le fruit] de son travail.

d. Selon al-Naǧğār, Dieu peut infliger une souffrance à l'enfant sans compensation. Cette [thèse] est soutenue par les spéculateurs du camp des traditionnistes. 
